\title{
A INTERFACE ENTRE PESQUISA E EXTENSÃO NA DISCUSSÃO DOS PARQUES LINEARES COMO ESTRATÉGIA DE REQUALIFICAÇÃO DA PAISAGEM URBANA
}

\author{
THE INTERFACE BETWEEN RESEARCH AND EXTENSION IN THE DISCUSSION OF \\ LINEAR PARKS AS A STRATEGY TO REHABILITATE URBAN LANDSCAPE
}

\author{
Renata Baesso Pereira* \\ Claudia Maria Lima Ribeiro** \\ Adriano Bueno, Daniel Henrique Ribeiro, Danilo Pena Maia, \\ Fernanda Martini, Maria Stella Angote, Ricardo Lazarin, \\ Rodrigo Roda e Viviane Bestane Bartolo***
}

\section{RESUMO}

Este artigo discute as práticas acadêmicas do grupo Programa de Ensino Tutorial no curso de Arquitetura e Urbanismo da Pontifícia Universidade Católica de Campinas relatando as experiências de um convênio firmado entre a Universidade e a Prefeitura Municipal de Campinas (SP) na elaboração do projeto de um parque linear. Busca-se refletir sobre o potencial de convênios como esse na elaboração de práticas de pesquisa e ensino de projeto que contemplam as diversas instâncias do urbanismo na escala do município. Identificou-se uma oportunidade de refletir criticamente sobre a criação de um parque linear como estratégia de requalificação da paisagem urbana, contribuindo para a estruturação do sistema de espaços livres da cidade de Campinas. Palavras-chave: Parque linear. Plano diretor. Paisagem urbana. Legislação urbana. Ensino de arquitetura e urbanismo.

\footnotetext{
ABSTRACT

This paper discusses the academic practices of the Programa de Ensino Tutorial (PET - Tutorial Teaching Program), a group composed of Architecture and City Planning students of the Pontifícia Universidade Católica de Campinas (SP). It reports the experiences resulting from an agreement between the University and the Municipal Government of Campinas to devise a linear park project. It seeks to reflect on the potential of such agreements as a means to develop both research and teaching practices based on projects involving different city planning agencies on a city scale. Additionally, it brings forth critical reflections on the creation of linear parks as a strategy to rehabilitate urban landscape and contribute to structure the open space system of the city of Campinas.

Keywords: Linear park. Master Plan. Urban landscape. Urban legislation. Teaching of architecture and city planning.

* Engenheira arquiteta pela Escola de Arquitetura da Universidade Federal de Minas Gerais (UFMG), mestra em Urbanismo pela Pontifícia Universidade Católica de Campinas (PUC-Campinas), doutora em História e Fundamentos da Arquitetura e do Urbanismo pela Faculdade de Arquitetura e Urbanismo da Universidade de São Paulo (FAUUSP). Docente do Programa de Pós-Graduação em Urbanismo (POSURB) e da Faculdade de Arquitetura e Urbanismo da PUC-Campinas. Membro do grupo de pesquisa "História das cidades: ocupação territorial e ideários urbanos", do Centro de Ciências Exatas, Ambientais e de Tecnologia (CEATEC) da PUC-Campinas.

CV: http://lattes.cnpq.br/9692163245601581

** Arquiteta urbanista e mestra em Urbanismo pela Faculdade de Arquitetura e Urbanismo da Pontifícia Universidade Católica de Campinas (PUC-Campinas), da qual é docente. CV http://lattes.cnpq.br/8945265611231056

*** Alunos do Programa de Educação Tutorial (PET) - Faculdade de Arquitetura e Urbanismo da PUC-Campinas que compõem a equipe do Projeto do Parque Linear da Lagoa.
} 
Renata Baesso Pereira, Claudia Maria Lima Ribeiro, Adriano Bueno, Daniel Henrique Ribeiro, Danilo Pena Maia, Fernanda Martini, Maria Stella Angote, Ricardo Lazarin, Rodrigo Roda e Viviane Bestane Bartolo

\section{INTRODUÇÃO}

\section{O PAPEL DO PROGRAMA DE EDUCAÇÃO TUTORIAL NO CURSO DE ARQUITETURA E URBANISMO DA PUC-CAMPINAS (SP) E AS REFLEXÕES SUSCITADAS SOBRE PLANEJAMENTO E PROJETO URBANO A PARTIR DE UM CONVÊNIO ENTRE A UNIVERSIDADE E O PODER PÚBLICO MUNICIPAL}

O Programa de Educação Tutorial (PET)' de grupos formados por alunos de graduação que se dedicam em tempo integral ao desenvolvimento de atividades acadêmicas coordenadas por um professor tutor. $O$ aluno ingressa no PET no primeiro ano da graduação e é desejável que permaneça até a conclusão do curso. Durante a permanência no Programa, os alunos planejam e realizam atividades de ensino, pesquisa e extensão que contribuem para sua formação e para o desenvolvimento de habilidades que muitas vezes não conseguem ser trabalhadas com a devida importância e tempo em sala de aula.

Cada grupo é formado por alunos de diferentes períodos do curso de graduação, o que proporciona troca de ideias e experiências colaborativas de aprendizagem em que os alunos em estágio mais avançado no curso se envolvem na orientação e aprendizagem dos alunos dos períodos iniciais. A constituição dos projetos e das ações dos grupos PET se fundamentam no trabalho coletivo e colaborativo como ferramenta e contexto. Como contexto o grupo é um espaço de construção coletiva a partir de distintas perspectivas e, dadas as suas características - participação voluntária, objetivos comuns, liberdade de expressão, diluição de hierarquia -, constitui-se uma ferramenta para o aprimoramento acadêmico de todos os envolvidos: alunos, tutores, professores colaboradores e comunidade discente. (FERREIRA, MARTINS, FREITAS, 2007).

A articulação entre ensino, pesquisa e extensão objetivada pelo PET favorece a interdisciplinaridade e a busca por novas práticas e experiências pedagógicas na graduação. Nesse sentido, a prática da pesquisa constitui elemento integrante e inovador do ensino na graduação superior e a extensão ${ }^{2}$ revela-se uma estratégia relevante para a efetiva interação com a sociedade. Abordadas de forma dialética, pesquisa e extensão podem conjugar-se num ensino científico e tecnicamente competente, com inserção política e fundamentado em princípios éticos. (MARTINS, 2007, p. 17-8).

\footnotetext{
Programa de Educação Tutorial (PET) foi criado em 1979 no conjunto das iniciativas de fortalecimento do ensino superior brasileiro conduzido pela Coordenação de Aperfeiçoamento de Pessoal de Nível Superior (CAPES) e teve sua gestão assumida pela Secretaria de Educação Superior, do Ministério da Educação (SESu/MEC) em 1999. Atualmente conta com 842 grupos ligados a diversas áreas do conhecimento, distribuídos em 121 instituições de ensino superior - públicas, privadas e comunitárias - por todo o país.

2 "A concepção definida pelo Fórum de Extensão dos Pró-Reitores das Universidades Públicas define a extensão como princípio educativo que comtempla o processo de produção do conhecimento por meio da dimensão investigativa e do contato com o real. A ênfase no processo, o reforço no coletivo institucional e não ao assistencialismo material e intelectual são elementos estruturantes de uma visão atual e progressista da extensão universitária." (MARTINS, 2007, p. 19).
} 
O PET Arquitetura e Urbanismo da PUC-Campinas é composto por um professor tutor, doze alunos bolsistas e até seis alunos voluntários, que participam das atividades com o mesmo envolvimento dos bolsistas. $\bigcirc$ grupo conta com sala própria na forma de um pequeno ateliê de projeto para o desenvolvimento de suas pesquisas, projetos e estudos. Como um dos objetivos do programa é tornar os bolsistas agentes multiplicadores de conhecimento, outros alunos do curso também frequentam o ateliê do PET e participam de grupos de estudo ou de trabalho liderados pelos bolsistas. Criado em 1992, o grupo PET Arquitetura e Urbanismo da PUC-Campinas busca desde a sua origem contribuir para a discussão do projeto pedagógico do curso, mostrando-se um relevante laboratório de experiências didáticas e pedagógicas.

Visando à implantação da metodologia proposta pelo PET no sentido de trabalhar de forma dialética a pesquisa e a extensão, bem como discutir efetivamente possíveis práticas de ensino que garantam a implementação das diretrizes do projeto pedagógico do curso, o PET Arquitetura e Urbanismo aderiu em 2014 ao Termo de Cooperação Técnica firmado entre a Pró-Reitoria de Graduação da PUC-Campinas e a Secretaria Municipal do Verde, Meio Ambiente e Desenvolvimento Sustentável (SVDS) da Prefeitura Municipal de Campinas (PMC), que tem por objetivo o desenvolvimento - pela Universidade e a colaboração de técnicos da prefeitura - de projetos na área ambiental a partir das diretrizes de planejamento da SVDS.

No âmbito desse convênio a SVDS apresentou diversas demandas para a elaboração de estudos de implantação de parques lineares em Campinas, previstos nos Planos Locais de Gestão (PLGs) das Macrozonas do município ${ }^{3}$. O PET Arquitetura e Urbanismo considerou o convênio uma oportunidade de trabalhar de forma interdisciplinar um projeto que aliasse a pesquisa a práticas de extensão. Identificou-se também uma oportunidade de reflexão crítica sobre o projeto de um parque linear como estratégia de requalificação da paisagem urbana, contribuindo para a estruturação do sistema de espaços livres na escala do município.

Parte-se da premissa de que nos cursos de Arquitetura e Urbanismo a formação dos alunos pode ser ampliada e aprofundada a partir do contato direto com a comunidade e com o desenvolvimento de estratégias interdisciplinares de pesquisa e extensão. Reflexões teóricas e práticas retroalimentam os conteúdos das disciplinas e

\footnotetext{
Em função do reconhecimento da heterogeneidade das áreas do município de Campinas, no Plano Diretor de 2006 foram definidas 9 Macrozonas, considerando-se para essa definição os aspectos físico-territoriais, socioeconômicos e ambientais identificados a partir das leituras e diagnósticos produzidos. De acordo com a Lei Complementar n 15 de 27 de dezembro de 2006 - Lei do Plano Diretor de Campinas (SP) - o Plano Local de Gestão (PLG) é uma ferramenta complementar de ordenamento do território a ser desenvolvido pelo Poder Executivo a partir de um processo participativo, em conformidade com o Estatuto da Cidade, para as 9 Macrozonas do município. Nos PLGs, a partir do detalhamento das diretrizes são definidas as normas urbanísticas, discriminando-se os usos permitidos, formas de ocupação do solo, restrições sobre edificações e/ou atividades, localização de equipamentos, indicação de medidas para a recuperação de espaços públicos de saneamento, infraestrutura e drenagem, hierarquização do sistema viário, indicação de medidas de proteção, valorização e recuperação do patrimônio cultural e ambiental. O PLG da Macrozona 9 é o Projeto de Lei Complementar No 17 de 2010. Disponível em: <http://www.campinas.sp.gov.br/governo/seplama/planos-locais-de-gestao/>. Acesso em: 5 mar. 2016.
} 
Renata Baesso Pereira, Claudia Maria Lima Ribeiro, Adriano Bueno, Daniel Henrique Ribeiro, Danilo Pena Maia, Fernanda Martini, Maria Stella Angote, Ricardo Lazarin, Rodrigo Roda e Viviane Bestane Bartolo

de projetos de pesquisa, produzindo novos saberes que podem ser colocados a serviço da comunidade.

No Brasil é prática recorrente que o Planejamento Urbano e o Projeto Urbano sejam tratados de maneira estanque tanto no ensino de graduação em Arquitetura e Urbanismo como nas práticas dos órgãos de gestão municipal. A escolha do tema parque linear - para desenvolvimento de projeto urbano que trabalha a interface entre planejamento urbano e projeto urbano - justifica-se como oportunidade de refletir sobre as contradições das políticas públicas ambientais voltadas para os espaços livres. A aproximação entre a universidade e o poder público municipal é uma oportunidade para os alunos de graduação se confrontarem com as vicissitudes dos órgãos de planejamento ambiental e de gestão municipal e refletirem sobre a formulação de um Projeto Urbano a partir das premissas do Planejamento Urbano, considerando suas interfaces e contradições e estabelecendo práticas projetuais que construam pontes entre estes dois momentos: o Plano e o Projeto.

O presente artigo tem o objetivo de relatar a experiência de elaboração do projeto do Parque Linear da Lagoa na região Noroeste de Campinas (Macrozona 9). A partir da discussão sobre a metodologia empregada para o desenvolvimento desse projeto, busca-se refletir o potencial de convênios como esse para a elaboração de práticas de pesquisa e ensino de projeto que contemplem as diversas instâncias do urbanismo na escala do município: planejamento, gestão, desenho urbano, projeto paisagístico.

\section{OS PARQUES LINEARES E AS ÁREAS DE PRESERVAÇÃO PERMANENTE URBANAS NA LEGISLAÇÃO AMBIENTAL, URBANÍSTICA E NO PLANO DIRETOR DE CAMPINAS (SP)}

Espaço livre é todo espaço não ocupado por um volume edificado: espaço-solo, espaço-água, espaço-luz ao redor das edificações a que as pessoas têm acesso. (MAGNOLI, 2006, p. 179).

Na cidade, o sistema de espaços livres é constituído por espaços livres de edificação, de propriedade pública ou privada [...] Os espaços livres públicos são os mais associados à vida urbana, frequentemente, locais de conflitos e acordos, de permanência ou circulação, da biodiversidade e da sociodiversidade. (BENFATTI; SILVA, 2013, p. 5).

No Brasil a abordagem contemporânea dos espaços livres urbanos tem privilegiado os aspectos ambientais. Nesse sentido são várias as cidades que propõem a implantação de parques lineares como alternativa de uso das áreas de fundo de vale e como estratégia de planejamento municipal. Do ponto de vista ambiental, a implantação de um sistema de parques lineares pode melhorar a drenagem, aumentando a quantidade de áreas permeáveis qualificadas no perímetro urbano, pode contribuir para a melhora do microclima e da qualidade do ar e buscar a reversão do estado de polvição e 
degradação dos cursos d'água. No planejamento urbano os parques lineares também têm sido usados como estratégia para prevenir as ocupações irregulares em áreas de fundo de vale urbanas municipais.

Em face da relevância das questões ambientais no cenário contemporâneo, a obrigatoriedade de manter ou regenerar as Áreas de Preservação Permanente (APPs) em áreas urbanas ganha força de lei e consolida-se com as alterações do Código Florestal (Lei N 4771/65) incluídas pela Medida Provisória N²166-67 de 2001 (BENFATTI; SILVA, 2013, p. 4). A discussão legal sobre as áreas de APPs urbanas passa em 2006 por uma revisão importante a partir da Resolução 369 do Conselho Nacional do Meio Ambiente (CONAMA) 4 . A abordagem anterior da legislação privilegiava exclusivamente os aspectos biofísicos e ambientais e foi revista em favor de critérios que consideram a realidade do meio urbano e o uso social das APPs:

\begin{abstract}
A legislação ambiental atuou nas últimas décadas na preservação das matas ciliares. Simultaneamente a legislação urbanística passou a considerar os cursos d'água como patrimônio urbano e paisagístico reconsiderando práticas correntes do passado como a canalização e recobrimento dos cursos d'água. De propriedade pública ou privada as áreas lindeiras aos cursos d'água passam a ser protegidas pela legislação ambiental. Isto implicou para muitas cidades em um acréscimo considerável de espaços livres de edificação no meio urbano. Assim, um novo e importante conjunto de áreas não edificadas estaria sendo incorporado ao conjunto geral de áreas que compõem o sistema de espaços livres da cidade. (BENFATTI; SILVA, 2013, p. 4).
\end{abstract}

A Seção III da Resolução 369 do CONAMA estabelece os parâmetros para a implantação de área verde de domínio público em APPs urbanas. Nesse caso a intervenção ou supressão de vegetação em APPs poderá ser autorizada pelo órgão ambiental competente, atendido o disposto no Plano Diretor Municipal (PDM). Considera-se área verde de domínio público o espaço que desempenha função ecológica, paisagística e recreativa, propiciando a melhoria da qualidade estética, funcional e ambiental da cidade, dotado de vegetação e espaços livres de impermeabilização.

Para além dos aspectos legais a serem considerados é importante destacar o papel histórico dos cursos d'água nas cidades brasileiras, com tradição vinculada ao despejo de dejetos. Essa situação fica mais evidente em áreas frágeis, decorrentes do processo histórico de urbanização onde a polarização entre centro e periferia, a despeito de não mais se configurar efetivamente dessa maneira, consolidou áreas de grandes precariedades. Esse conjunto de áreas originárias dos cursos d'água urbanos tem como característica formal a linearidade e a conectividade entre elas, perfazendo áreas livres de grande extensão que, se apropriadas para o uso público e recebendo ações efetivas de desenho urbano, assumem sua vocação para a implementação de parques lineares urbanos. A partir dessa perspectiva os parques lineares permitem responder à legislação

Resolução CONAMA Nº 369 de 28 de março de 2006. Dispõe sobre os casos excepcionais, de utilidade pública, interesse social ou baixo impacto ambiental, que possibilitam a intervenção ou supressão de vegetação em Área de Preservação Permanente-APP. Diário Oficial da União, 29 mar. 2006, Seção 1, p. 150-151. 
Renata Baesso Pereira, Claudia Maria Lima Ribeiro, Adriano Bueno, Daniel Henrique Ribeiro, Danilo Pena Maia, Fernanda Martini, Maria Stella Angote, Ricardo Lazarin, Rodrigo Roda e Viviane Bestane Bartolo

de APPs e podem ser pensados como estratégias de requalificação da paisagem de uma cidade, contribuindo para a constituição do seu sistema de espaços livres públicos ao gerar conectividade para pessoas a partir da incorporação de formas de mobilidade não motorizadas (bicicleta e caminhada) e de equipamentos sociais, culturais, esportivos e recreativos em seus programas. Ao atribuir uso às APPs urbanas, áreas tradicionalmente degradadas nas cidades brasileiras, o projeto de parques lineares pode contribuir para garantir a paisagem como um direito da cidade.

A estratégia de implantar parques lineares nas APPs foi incorporada pelo PDM de Campinas (SP) em 2006 e as contradições ligadas a essa abordagem de planejamento urbano são discutidas no presente artigo. $O$ trabalho de Silva e Benfatti (2013) já apontou fragilidades desse PDM, que privilegia a abordagem quantitativa em relação à criação de parques lineares no município. No item relativo à política de meio ambiente os autores destacam o subitem "Eixos Verdes", que tem por objetivo "[...] elevar o índice de área verde do município ( $\mathrm{m}^{2} /$ habitante), de maneira a atingir e superar os padrões recomendados" ${ }^{\text {. }}$. Os Parques Lineares são uma modalidade de "eixos verdes" e, segundo o PDM, deverão estar de acordo com o conceito de recuperação ambiental das APPs e compatibilizados com atividades de lazer e recreação. Portanto, de acordo com o PDM de Campinas (2006), os parques lineares deverão enquadrar-se aos preceitos definidos pela Resolução CONAMA 369, desempenhando papel sobretudo quantitativo no planejamento ambiental do município. (BENFATTI; SILVA, 2013, p. 12).

Apesar das contradições ligadas ao tema, para as cidades brasileiras há consequências positivas associadas à incorporação das questões relacionadas à preservação das APPs no planejamento urbano. De modo estruturalmente positivo, cria-se um estoque de áreas a serem preservadas para as futuras gerações, que constitui uma reserva de espaços livres para eventual aproveitamento social. Garante-se também a permanência da vegetação no contexto urbano. Contudo as APPs se constituem em figuras urbanas novas, sendo que as metodologias de projeto urbano e os mecanismos de gestão para essas áreas precisam ser aperfeiçoados. (MACEDO; QUEIROGA; DEGREAS, 2012).

\section{O PROJETO DO PARQUE LINEAR DA LAGOA EM CAMPINAS (SP): INVESTIGAÇÕES SOBRE A INTERFACE ENTRE PLANEJAMENTO E DESENHO URBANO}

O envolvimento do grupo PET Arquitetura e Urbanismo da PUC-Campinas no projeto de um parque linear é uma tentativa de discutir, a partir da articulação entre pesquisa e extensão, as contradições das políticas públicas ambientais de Campinas voltadas para os espaços livres urbanos e contribuir com subsídios concretos que possam discutir a relação dialética que deveria existir entre o planejamento urbano e o desenho urbano.

Apesar da exigência do Estatuto da Cidade (2001) de gestão participativa no processo de planejamento urbano, o modelo vigente no Brasil ainda define o macrozoneamento

As Vias Verdes, ou Eixos Verdes, foram instituídos pelo PDM de Campinas - Lei Complementar n 15/07 nos artigos 37 e 38 . 
de "cima para baixo". As soluções de planejamento lançam diretrizes para grandes zonas urbanas, dificultando o entendimento das demandas das comunidades locais, o que em muitos casos favorece a lógica imobiliária. (ANDRADE, 2014, p. 41-42).

No Brasil o planejamento urbano baseado no zoneamento trabalha com diretrizes gerais e se distanciou dos estudos da forma urbana sem valorizar a heterogeneidade espacial da escala mais refinada.

Em muitas cidades, o detalhamento da escala local fica a critério das leis de uso e ocupação do solo - LUOS - que lançam apenas diretrizes de projeto com foco nas dimensões funcionais e econômicas, sem preocupações com outras expectativas sociais, tais como ecológicas, bioclimáticas, culturais (identidade e orientabilidade), afetivas, sociológicas, expressivas, estéticas e simbólicas. (ANDRADE, 2014, p. 42).

São ações muito distantes do desenho urbano, sobretudo daquele sensível à água no meio urbano. Em geral os planos diretores não fazem uma abordagem integrada com as políticas ambientais e demais políticas setoriais, que continuam sendo tratadas de forma segmentada. (COSTA; CAMPANATE; ARAÚJO, p. 177). Ainda ocorre falta de integração dos órgãos do governo, que produzem diretrizes pouco específicas e algumas vezes incoerentes com a realidade das cidades. (ANDRADE, 2014, p. 41). Em pesquisa realizada pela Rede de Avaliação e Capacitação para Implementação dos Planos Diretores Participativos, coordenada pela Secretaria Nacional de Programas Urbanos do Ministério das Cidades (2011), sobre "A Dimensão Ambiental nos Planos Diretores de Municípios Brasileiros", revelou-se que em geral os planos diretores analisados tratam a questão do meio ambiente apenas sob o prisma da agenda verde, ou seja, da arborização urbana e da preservação de espaços livres e unidades de conservação. A grande maioria dos planos não foi capaz de fazer a integração necessária com a chamada agenda marrom. É como se lotear, construir e ocupar o espaço urbano fossem atividades "não ambientais" e somente a ação de preservação, como sinônimo de "não ocupar" ou de "manter intocado", fosse afeita ao campo ambiental. (COSTA; CAMPANATE; ARAÚJO, p. 178).

Para a elaboração do projeto do Parque Linear da Lagoa, a equipe do PET Arquitetura e Urbanismo da PUC-Campinas analisou tanto o PDM de Campinas (2006), que se enquadra plenamente nas características gerais expostas no artigo em relação ao planejamento urbano brasileiro quanto o PLG-MZ9, onde se encontra a área de estudo. Verificou-se que a questão dos parques lineares é tratada de forma muito generalizada na legislação urbanística do município e não fica definido o órgão municipal responsável pela implantação dos parques lineares na cidade. Formalmente a SVDS tem cuidado do tema, mas não conta com corpo técnico, recursos e estrutura adequados para o desenvolvimento dos projetos. A desarticulação entre as ações das Secretarias de Planejamento Urbano, Habitação e Meio Ambiente também compromete de forma significativa a implantação de parques lineares em Campinas.

A metodologia empregada no desenvolvimento do projeto do Parque Linear da Lagoa se pautou em discussão teórica contemplando aspectos conceituais relaciona- 
Renata Baesso Pereira, Claudia Maria Lima Ribeiro, Adriano Bueno, Daniel Henrique Ribeiro, Danilo Pena Maia, Fernanda Martini, Maria Stella Angote, Ricardo Lazarin, Rodrigo Roda e Viviane Bestane Bartolo

dos ao tema, revisão bibliográfica de estudos recentes e questões da prática projetual - a partir do levantamento de estudos de caso implantados no Brasil e exterior -, levantamento de legislação específica relacionada às APPs urbanas, levantamento documental na forma de cartografia do município de Campinas, plantas e fotos aéreas da área do projeto, levantamento de campo pela equipe de pesquisadores com registros fotográfico, gráfico e descritivo na forma de fichas de observação. $\mathrm{Na}$ Prefeitura de Campinas os principais interlocutores foram técnicos, planejadores e gestores da SVDS, que possuem formação bastante diversificada: arquitetos urbanistas, geógrafos, ecólogos, engenheiros químicos e biólogos. Dada a forma de gestão compartimentada dos temas relacionados ao meio ambiente urbano pela Prefeitura de Campinas não houve possibilidade de diálogo com as Secretarias de Habitação de Planejamento Urbano.

A área do projeto foi definida a partir da demanda da SVDS e localiza-se na Macrozona 9 (MZ9) junto ao córrego da Lagoa, afluente do ribeirão Quilombo. A extensão da área é compatível com as possibilidades de desenvolver um projeto que discuta questões na escala do planejamento e do desenho urbano e paisagístico. Uma das premissas sustentadas pelo PET era a necessidade de contato com os moradores dos bairros da área de projeto para conhecer suas demandas e desejos em relação aos espaços livres. A equipe do PET participou de reuniões com a sociedade civil organizadas através da Organização Não Governamental (ONG) Rede Abraço, que atua na região. A colaboração dos agentes de saúde, funcionários dos centros de saúde dos bairros da área de projeto nas visitas de campo para levantamentos foi fundamental, pois são esses profissionais que têm maior conhecimento da realidade dos bairros e conhecem de fato os moradores. O projeto foi dividido em três etapas: Etapa 1 - Fundamentação conceitual e levantamentos da área de estudo; Ełapa 2 - Diretrizes de Projeto; Etapa 3 - Proposta.

\section{ETAPA 1 - FUNDAMENTAÇÃO CONCEITUAL E LEVANTAMENTOS DA ÁREA DE ESTUDO}

Na primeira etapa do projeto procedeu-se à discussão teórica contemplando aspectos conceituais relacionados ao tema, à revisão bibliográfica e ao levantamento de estudos de caso de parques lineares implantados no Brasil e no exterior. Com relação à legislação, os principais documentos levantados que fundamentaram as análises foram o PDM de Campinas (2006), o Caderno de Subsídios para o PLG - MZ9 e o próprio PLG - MZ 9 com todos os mapas. Também foi feita leitura crítica da Resolução 369 do CONAMA (2006).

A figura 1 apresenta a divisão das nove Macrozonas do município de Campinas. A MZ9 se encontra na porção Noroeste do município - compreendendo as regiões do distrito de Nova Aparecida e dos bairros Parque Santa Bárbara, Vila Boa Vista, Parque Via Norte e a região dos Amarais, Jardim São Marcos e Jardim Santa Mônica. É uma região que se desenvolve na confluência de grandes eixos viários estruturadores, as 
rodovias Anhanguera, D. Pedro I, Adalberto Panzan (via de conexão entre as rodovias Anhanguera/Bandeirantes). É contígua a grandes barreiras físicas, como as fazendas Chapadão (Exército) e Santa Elisa, que funcionam como elementos segregadores, dificultando a articulação dessa macrozona com a malha urbana do município. A MZ9 apresenta acentuado processo de conurbação com os municípios de Hortolândia e Sumaré, possui área de 28,79 km² - correspondendo a 3,61\% da área do município - e é formada apenas por porção urbana, não havendo área rural.

A população total da MZ9 era de 75.747 mil habitantes segundo o Censo de 2000, representando 7,81\% da população total do município. A população favelada da MZ9, que se concentra principalmente nas regiões dos Jardins São Marcos, Sta. Mônica, Campineiro e Boa Vista (ao longo dos leitos férreos), era da ordem de 16.645 mil habitantes, representando 13,04\% da população favelada do município. A renda familiar dos habitantes é predominantemente média-baixa e baixa. A MZ9 apresenta mescla de usos habitacionais de baixa renda com usos comerciais e industriais. (Caderno de Subsídios - PLG - MZ9).

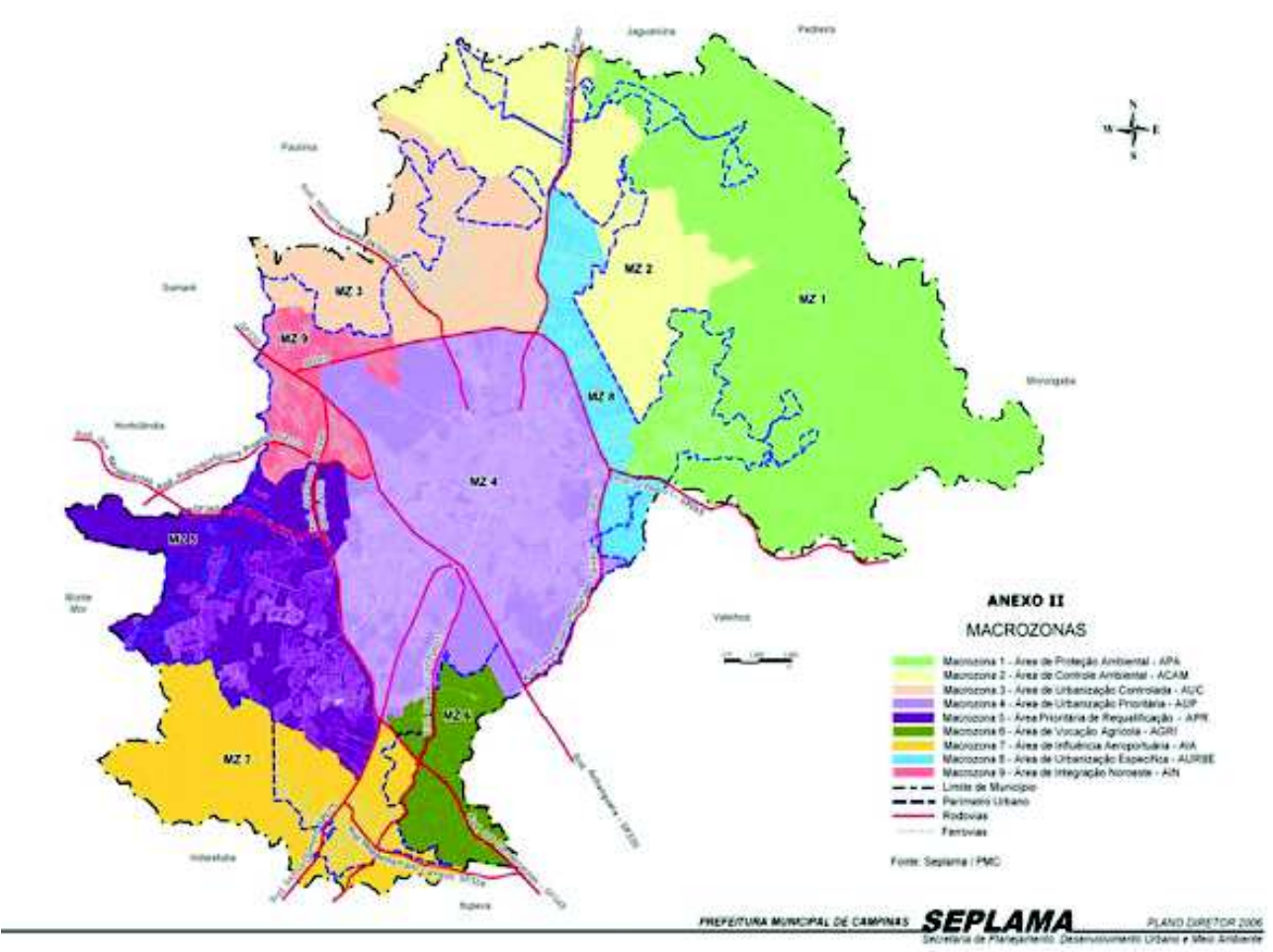

Figura 1 Mapa das Macrozonas de Campinas de acordo com o Plano Diretor de 2006.

Fonte: Prefeitura de Campinas. Disponível em: <http://www.campinas.sp.gov.br/governo/seplama/publicacoes/ planodiretor2006/mapas/mapa32.jpg >. Acesso em: 5 out. 2016.

De acordo com o PLG - MZ9 a área é drenada pelo ribeirão Quilombo e seus afluentes (córregos da Lagoa, da Boa Vista, do Pari, entre outros), além de abarcar uma porção da bacia do córrego Piçarrão. Esses cursos d'água são responsáveis pelo abastecimento de algumas cidades vizinhas e constituem uma rede de conexão entre 
Renata Baesso Pereira, Claudia Maria Lima Ribeiro, Adriano Bueno, Daniel Henrique Ribeiro, Danilo Pena Maia, Fernanda Martini, Maria Stella Angote, Ricardo Lazarin, Rodrigo Roda e Viviane Bestane Bartolo

as diversas e vastas várzeas ali ocorrentes com potencial para formação de corredores ecológicos, implantação de áreas verdes, espaços produtivos e de requalificação urbana. A bacia hidrográfica do ribeirão Quilombo possui em torno de $396 \mathrm{~km}^{2}$, abrangendo os municípios de Americana, Nova Odessa, Sumaré, Hortolândia e parte dos municípios de Paulínia e Campinas.

Os cursos d'água da MZ9 e suas áreas marginais encontram-se em grande medida degradados e desprovidos de vegetação natural, apresentando em diversos pontos despejo de entulhos ou algum tipo de atividade agropecuária. Observa-se em alguns pontos o desenvolvimento espontâneo de remanescentes de matas ciliares e campos de várzea e plantios realizados pela comunidade. Há ocorrência de ocupações irregulares e sub-habitações nessas localizações e a prefeitura tem procedido a ações de remoção da população nas áreas alagáveis. A MZ9 possui 363,70 hectares de APPs (figura 2), que representam 12,69\% de seu território. Apenas 78,78 hectares $(21,66 \%)$ estão em situação de conformidade com a legislação e 284,92 hectares (78,34\%) estão em situação de conflito, ou seja, desprovidos de vegetação natural. As APPs em áreas de conflito estão apresentadas em vermelho no mapa da figura 2. Esse quadro explica de certa forma a grande quantidade de ocupações irregulares das planícies de inundação e áreas marginais aos cursos d'água, expondo a população ao risco de enchentes. O plano proposto pela Prefeitura de Campinas de um sistema integrado de áreas verdes para a MZ-9, exposto na figura 3, converte grande parte das APPs em parques lineares combinados com uma rede de ciclovias. Embora a área ao longo do córrego da Lagoa seja densamente ocupada, é classificada como corredor verde e não como parque linear. $\bigcirc$ mapa da figura 4 demonstra que a área ao longo do córrego da Lagoa, objeto do projeto desenvolvido pelo PET, é composta por ocupações e favelas.

Na etapa 1 do projeto também foi feito levantamento físico e dos aspectos sociais da área de estudo. Cartografia, plantas e fotos aéreas da área do projeto foram elencados para preparar a equipe antes das visitas técnicas. A figura 6 sintetiza o levantamento de uso e ocupação do solo da área de intervenção. Todos os equipamentos urbanos foram levantados pela equipe de projeto e estão apresentados na figura 7. O levantamento de campo feito pela equipe de pesquisadores contou com registros fotográficos, gráficos e descritivos na forma de fichas de observação. Em algumas das visitas a equipe foi acompanhada dos agentes de saúde dos bairros. Algumas fotos desses levantamentos de campo estão expostas nas figuras 8, 9, 10 e 11 .

\section{ETAPA 2 - DIRETRIZES DE PROJETO}

A partir dos levantamentos realizados, procedeu-se à etapa de elaboração de diretrizes para o projeto. Pensando nas questões ambientais e de drenagem urbana, verificou-se a possibilidade de o projeto gerar impactos positivos desde a escala regional e metropolitana, compreendendo a bacia do Quilombo, até a dos bairros adjacentes, na medida em que qualifica os espaços livres públicos. 


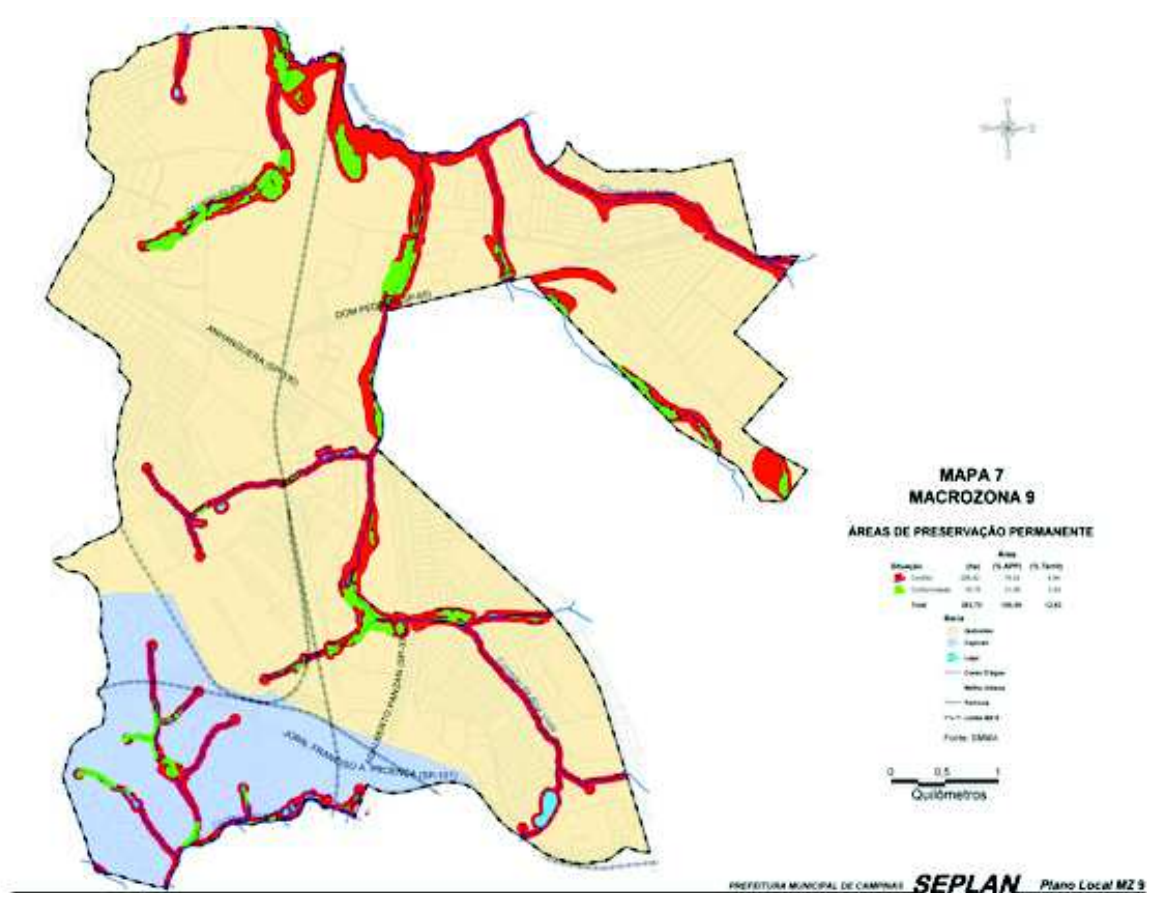

Figura 2 Mapa das APPs da MZ9.

Fonte: Caderno de Subsídios do PLG - MZ 9 - Prefeitura de Campinas. Disponível em:

$<$ http://www.campinas.sp.gov.br/governo/seplama/planos-locais-de-gestao/doc/mz9_mapas.pdf>. Acesso em: 4 out. 2016.

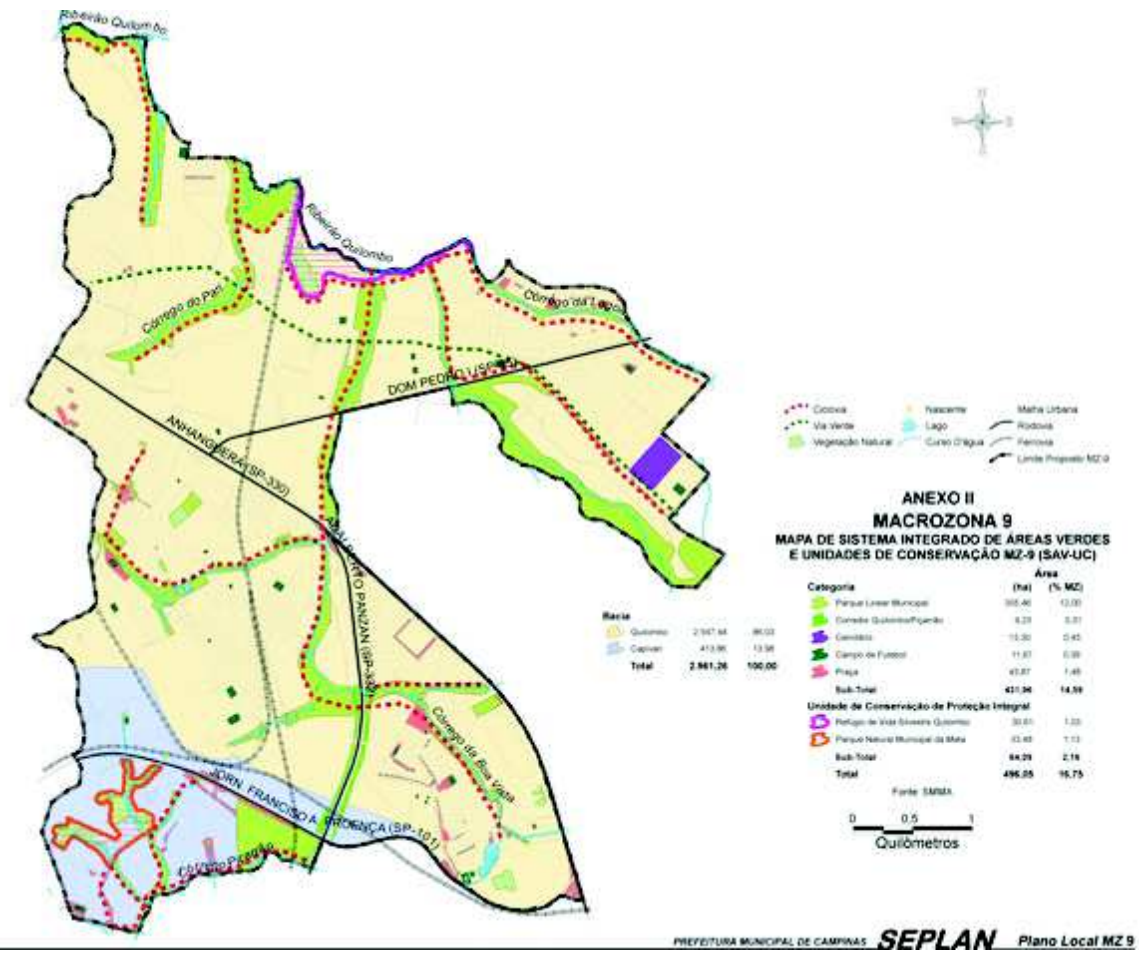

Figura 3 Mapa do Sistema Integrado de Áreas Verdes e unidades de conservação da MZ-9. Fonte: Caderno de Subsídios do PLG - MZ - 9 - Prefeitura de Campinas. Disponível em: <http://www.campinas.sp.gov.br/governo/seplama/planos-locais-de-gestao/doc/mz9_mapas.pdf>. Acesso em: 4 out. 2016. 
Renata Baesso Pereira, Claudia Maria Lima Ribeiro, Adriano Bueno, Daniel Henrique Ribeiro, Danilo Pena Maia, Fernanda Martini, Maria Stella Angote, Ricardo Lazarin, Rodrigo Roda e Viviane Bestane Bartolo

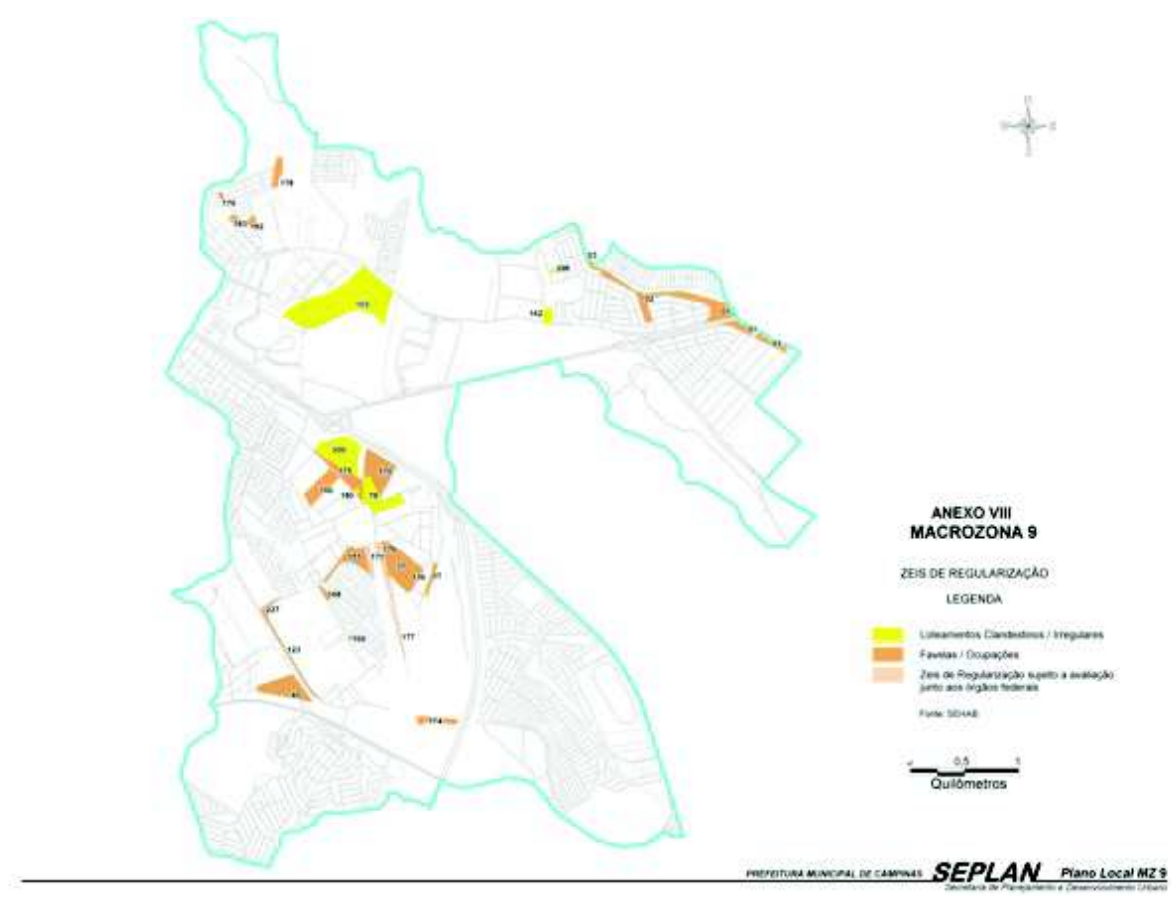

Figura 4 Mapa das Zonas Especiais de Interesse Social (ZEIS) de Regularização da MZ-9. Observa-se que a área do projeto junto ao córrego da Lagoa possui favelas e ocupações.

Fonte: Caderno de Subsídios do PLG - MZ - 9 - Prefeitura de Campinas. Disponível em: <http://www.campinas. sp.gov.br/governo/seplama/planos-locais-de-gestao/doc/mz9_mapas.pdf>. Acesso em: 4 out. 2016.

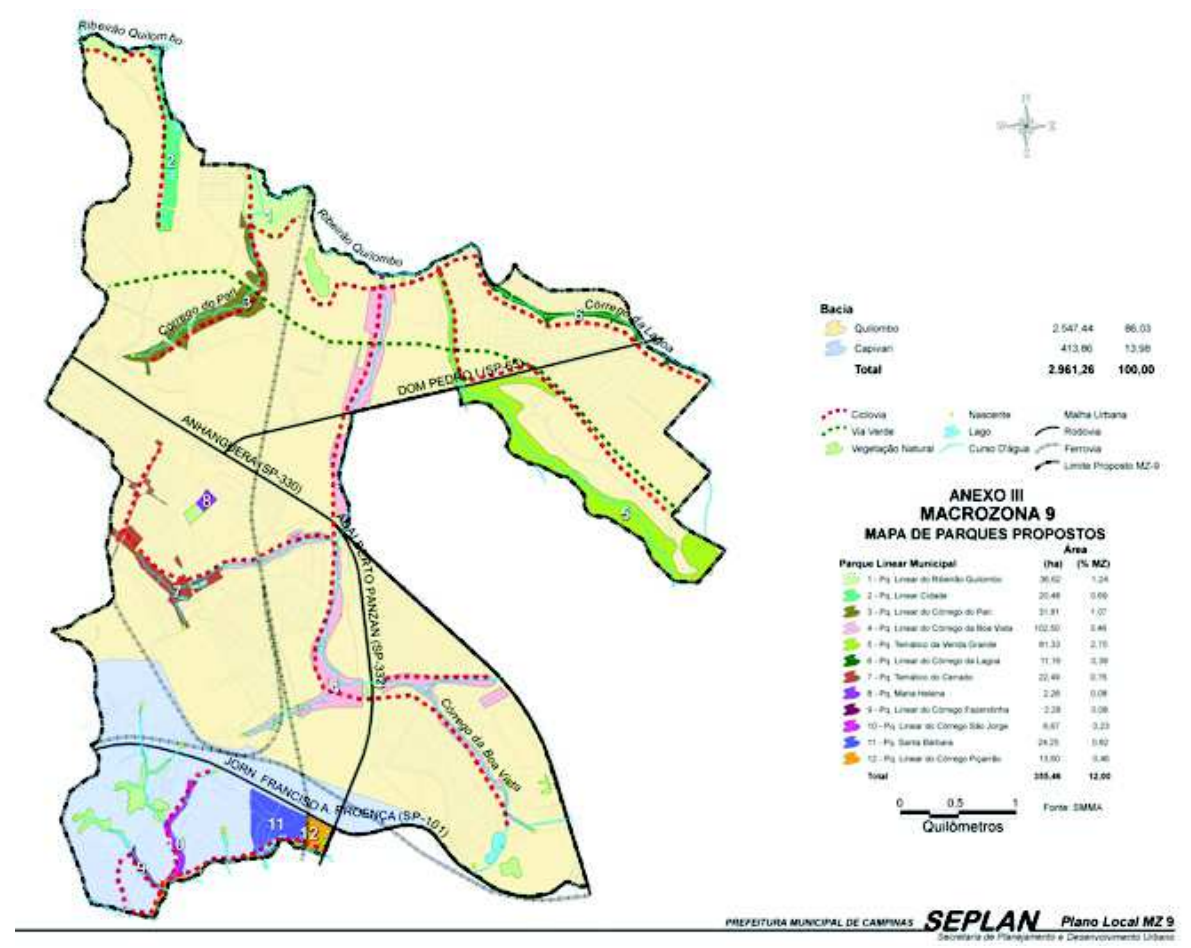

Figura 5 Mapa dos parques propostos para a MZ9. O parque junto ao córrego da Lagoa está nas diretrizes para a área. Fonte: PLG - MZ - 9 - Prefeitura de Campinas. Disponível em:

$<$ http://www.campinas.sp.gov.br/governo/seplama/planos-locais-de-gestao/doc/mz9 mapas.pdf>. Acesso em: 4 out. 2016. 


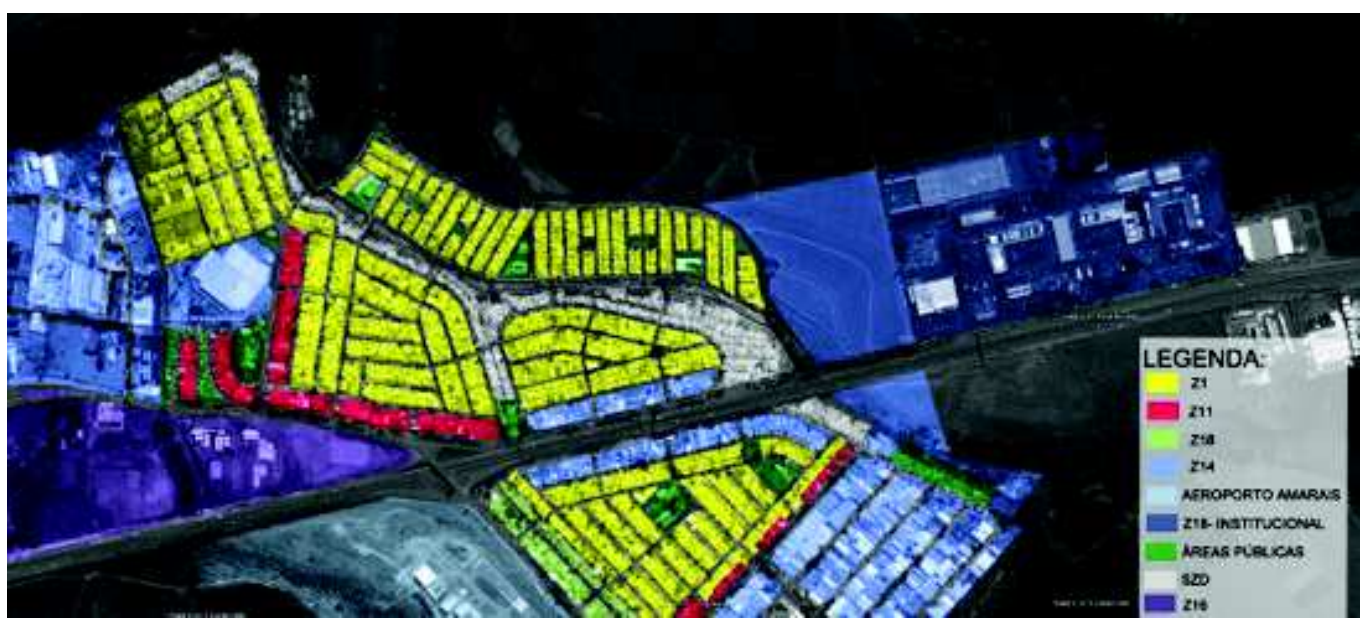

Figura 6 Levantamento de Uso e Ocupação do Solo.

Fonte: Elaborada pela equipe do PET.

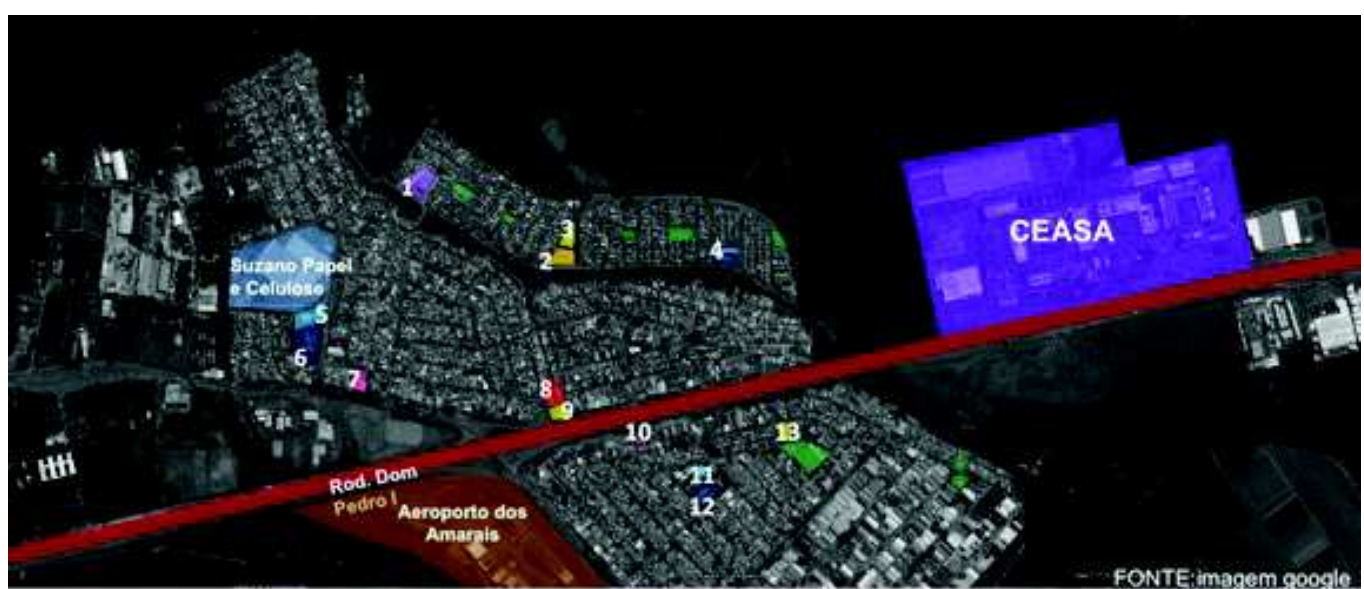

Escola Estadual
CEMEIs
EMEFs
EMEls
Centro de Saúde
CEU
Nave Maae
Áreas Livres

1- Centro de Artes e Esportes

Unificado (CEU)

2- Nave Mãe

3- CEMEI Fernando Alpheo Miguel

4- Escola FDE

5- Centro de Saúde Jd. Säo Marcos

6- Escola Estadual Professora

Castinauta de Barros Mello e

Albuquerque Sampaio

Figura 7 Levantamento dos equipamentos urbano.

Fonte: Elaborada pela equipe do PET.

7- EMEI Roberto T.

8- EMEF Padre José Narciso

9. CEMEI Roberto T, Sampaio

10- EMEI Esperança do Amanhā

11- Centro de Saúde Jd. Santa Monica

12- Escola Estadual Trinta e Um de Março

13- CEMEI Aparecida Cassiolato 


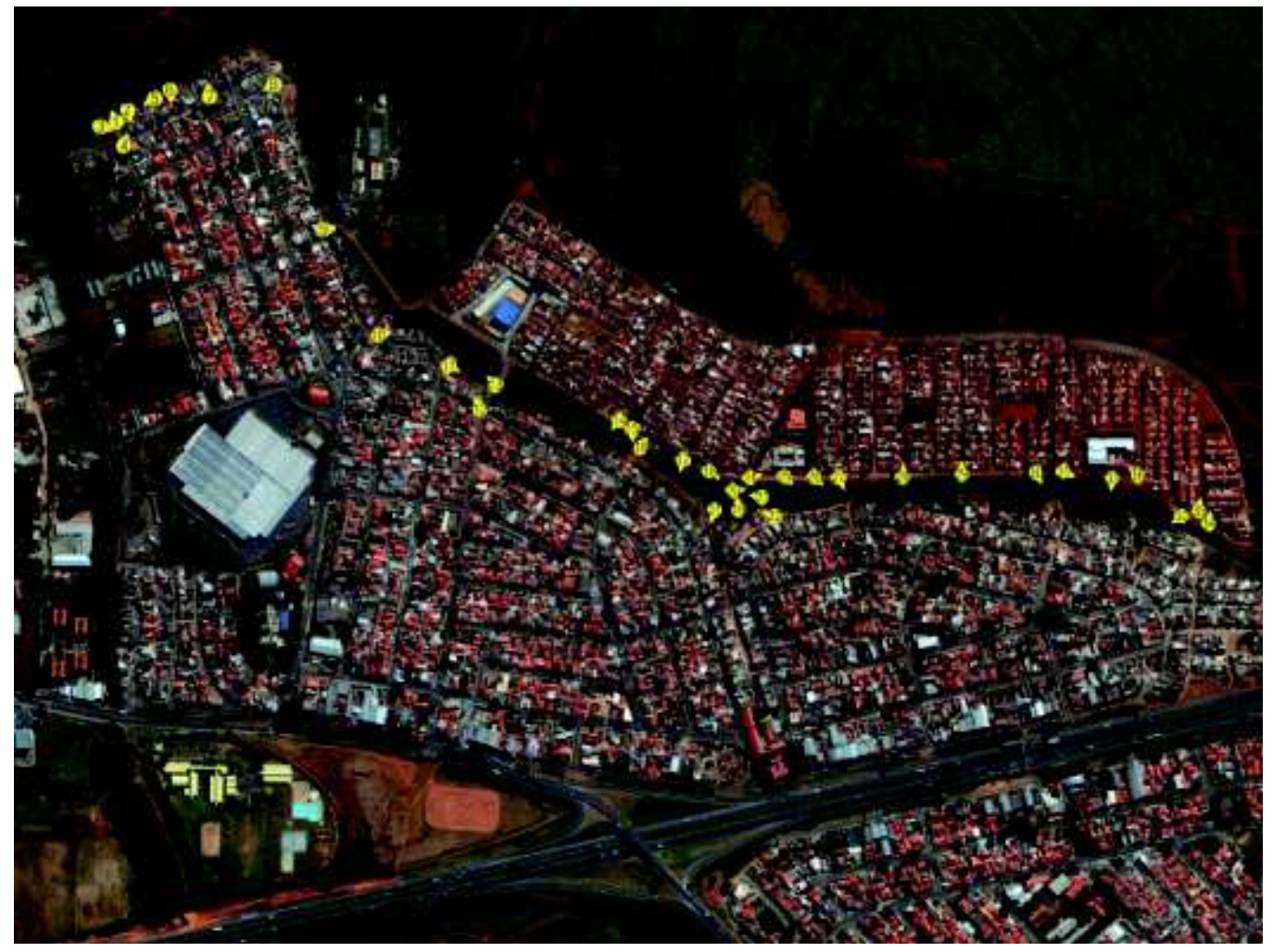

Figura 8 Mapeamento das fotos das visitas de campo.

Fonte: Elaborada pela equipe do PET.

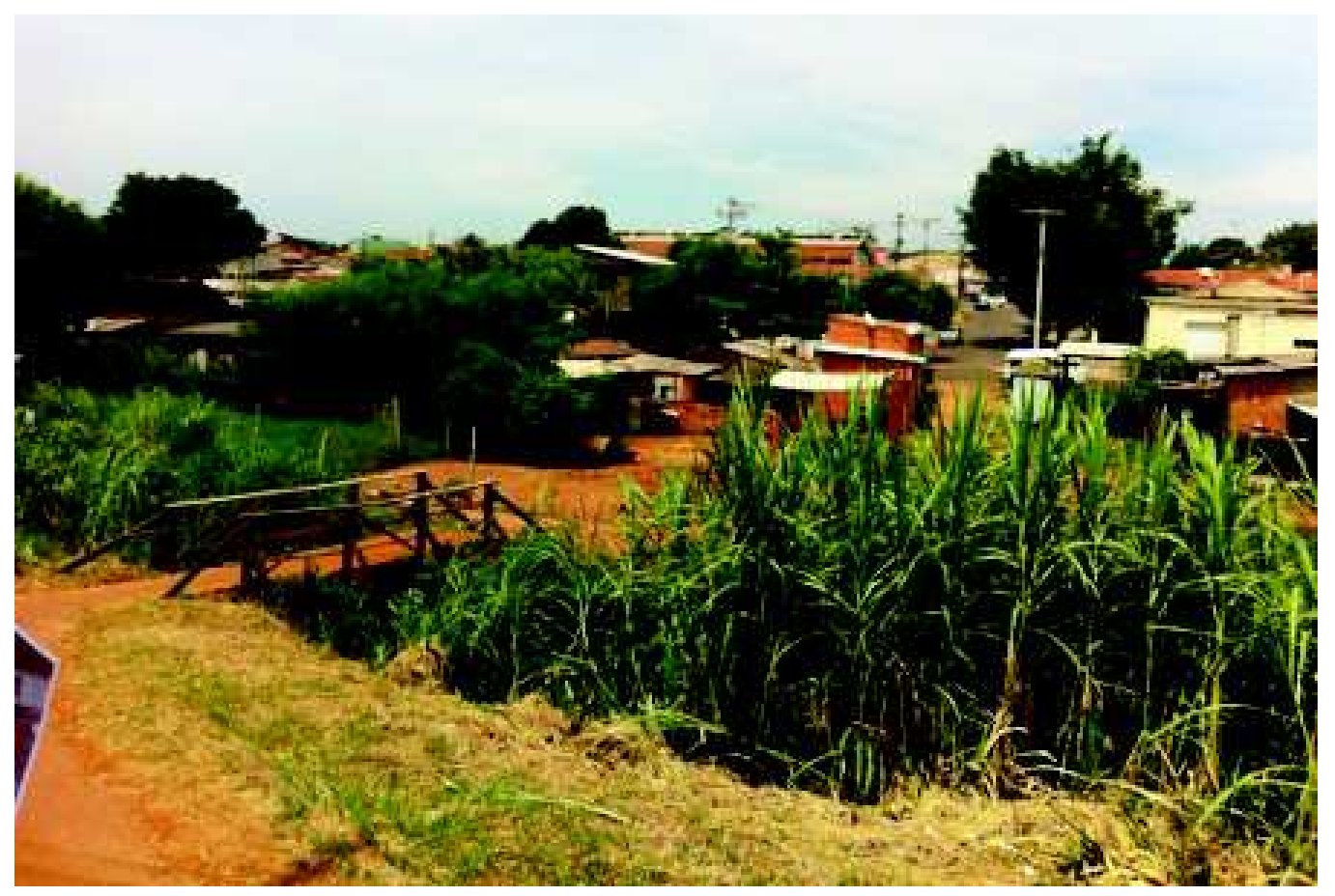

Figura 9 Visita de campo feita pela equipe do PET. Transposição de pedestres sobre o córrego da Lagoa. Foto: Daniel Henrique Ribeiro, 2015. 


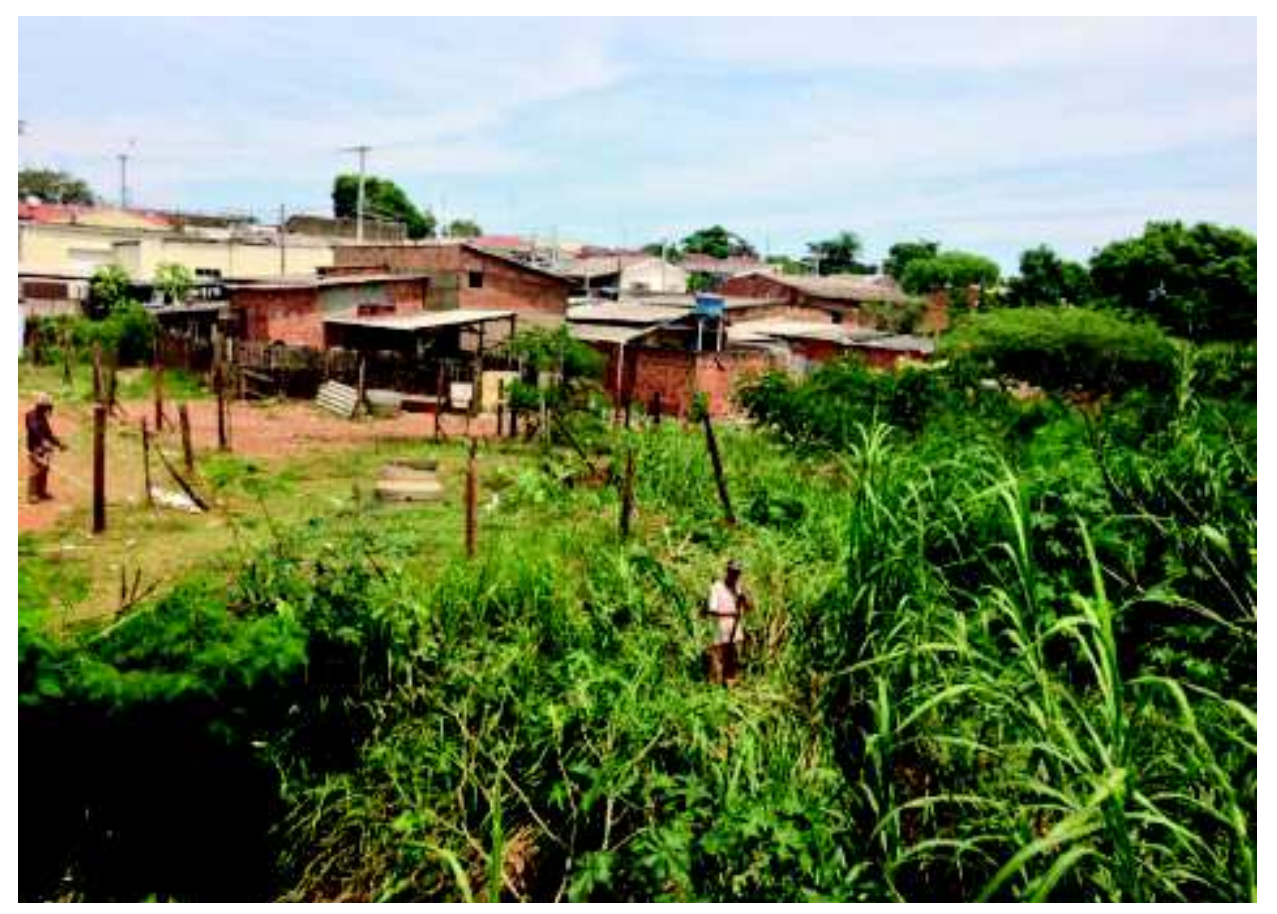

Figura 10 Visita de campo feita pela equipe do PET. Ocupação das margens do córrego da Lagoa. A prefeitura já iniciou o processo de remoção de famílias em áreas de risco junto ao córrego. Foto: Danilo Pena Maia, 2015.

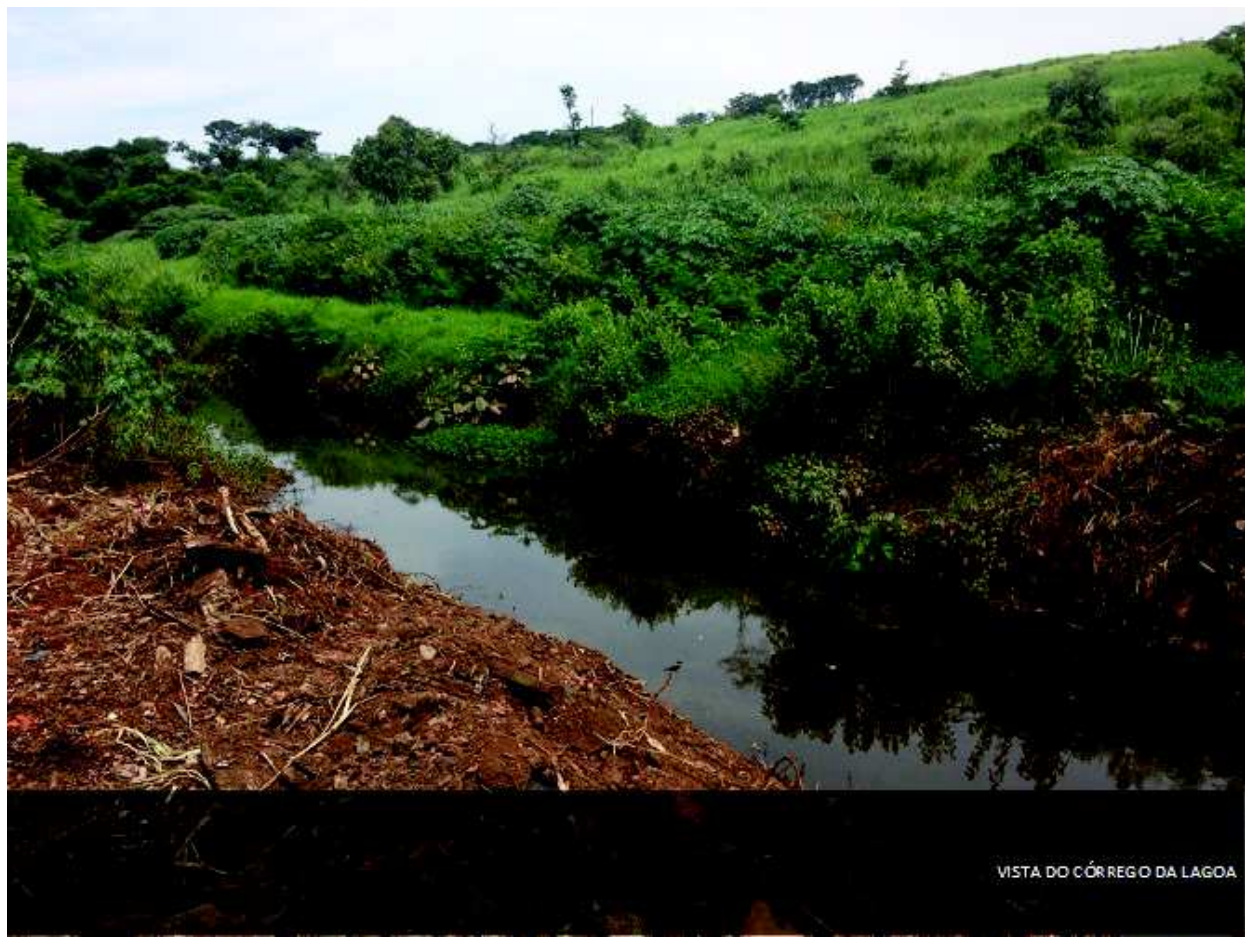

Figura 11 Visita de campo feita pela equipe do PET. Margens do córrego da Lagoa em trecho pouco urbanizado.

Foto: Viviane Bestane Bartolo, 2015. 
Renata Baesso Pereira, Claudia Maria Lima Ribeiro, Adriano Bueno, Daniel Henrique Ribeiro, Danilo Pena Maia, Fernanda Martini, Maria Stella Angote, Ricardo Lazarin, Rodrigo Roda e Viviane Bestane Bartolo

Do ponto de vista ambiental as principais diretrizes do projeto são: soluções para drenagem e contenção de cheias na região; contribuir para a recomposição da mata ciliar com arborização nativa e recuperação das margens do córrego da Lagoa, cuidando de processos de erosão e assoreamento; implantação de dispositivos de passagem de fauna.

Do ponto de vista de requalificação da paisagem, as diretrizes privilegiam o potencial de conectividade de um corredor verde e sua relação com equipamentos urbanos já existentes, outros espaços públicos e a importância das travessias para pedestres e ciclistas conectando os bairros da região. As diretrizes de projeto estão sintetizadas no mapa da figura 12, e a figura 13 destaca a relação entre a área do Parque Linear da Lagoa com o primeiro traçado proposto para a ciclovia e os demais espaços livres já existentes na região.

A equipe do PET participou de reuniões com a ONG Rede Abraço em que foram apresentados os objetivos do projeto para os líderes da comunidade. Esses contatos abriram caminho para o planejamento mais participativo e o esclarecimento da intenção do projeto presente no campo de possibilidades e estudos acadêmicos. Sempre foi colocado de forma muito clara para a comunidade que o projeto não tinha garantias por parte da Prefeitura de Campinas de ser implantado. De forma geral, as diretrizes do projeto atenderam as expectativas da comunidade em questão.

\section{ETAPA 3 - PROPOSTA}

A partir das diretrizes gerais foram detalhados elementos do projeto urbano e paisagístico. Entre as propostas do trabalho estão a implantação de pista de skate e um anfiteatro em área alagável a fim de garantir entretenimento para os adolescentes da região e evitar enchentes tal como exposto nos croquis das figuras 14, 15, 16 e 17. Outra proposta do grupo é a implantação de uma ciclovia com cerca de 2 quilômetros de extensão, melhorando a acessibilidade para os moradores e ligando o bairro ao comércio e às Centrais de Abastecimento de Campinas S/A (CEASA). O trajeto da ciclovia pode ser avaliado na implantação geral do projeto (figura 18). As transposições de pedestres foram propostas de acordo com a localização dos equipamentos urbanos e o sistema viário (figuras 19 a 34).

Foram avaliadas as áreas mais adequadas para a recomposição da vegetação, com espécies nativas formando maciços, e as áreas com vocação para instalação de equipamentos de lazer, cultura e esporte. Os percentuais de impermeabilização e alteração para ajardinamento limitados a respectivamente 5\% e 15\% da área total da APP foram respeitados de acordo com a resolução 369 do CONAMA. Soluções técnicas adequadas para as bacias de contenção também foram avaliadas, buscando aliar o desenho da paisagem com as soluções de drenagem. As soluções propostas podem ser avaliadas nas figuras 18 a 34 . 


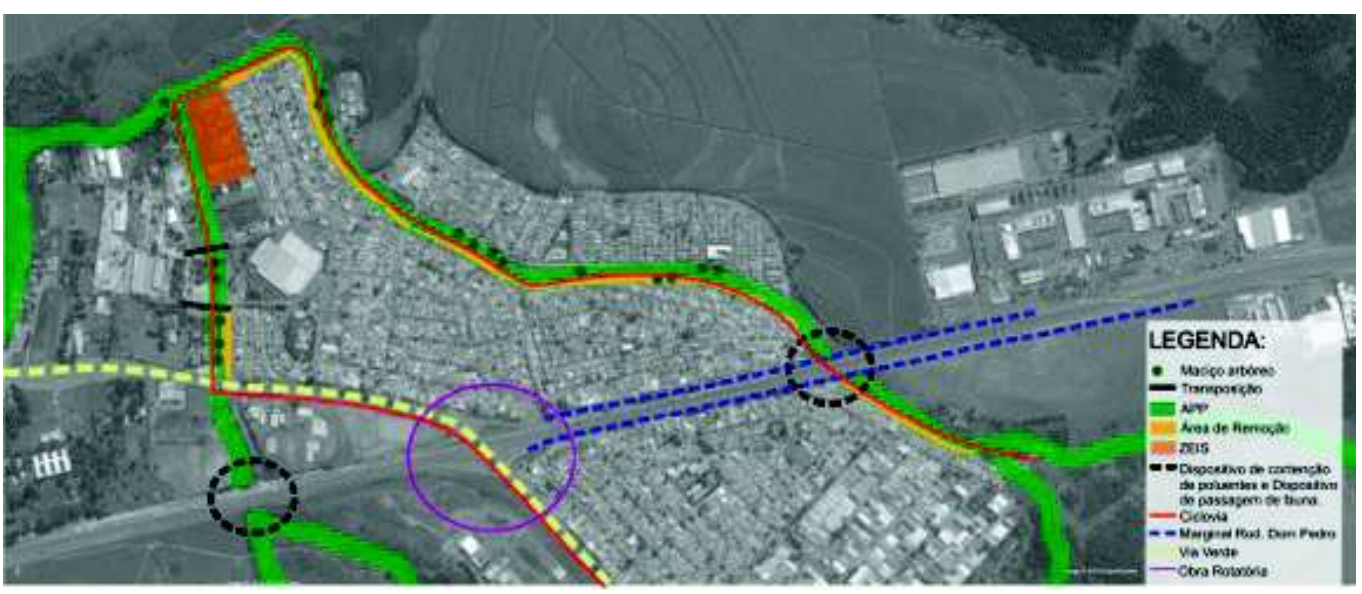

Figura 12 Planta síntese das Diretrizes de Projeto.

Fonte: Elaborada pela equipe do PET.

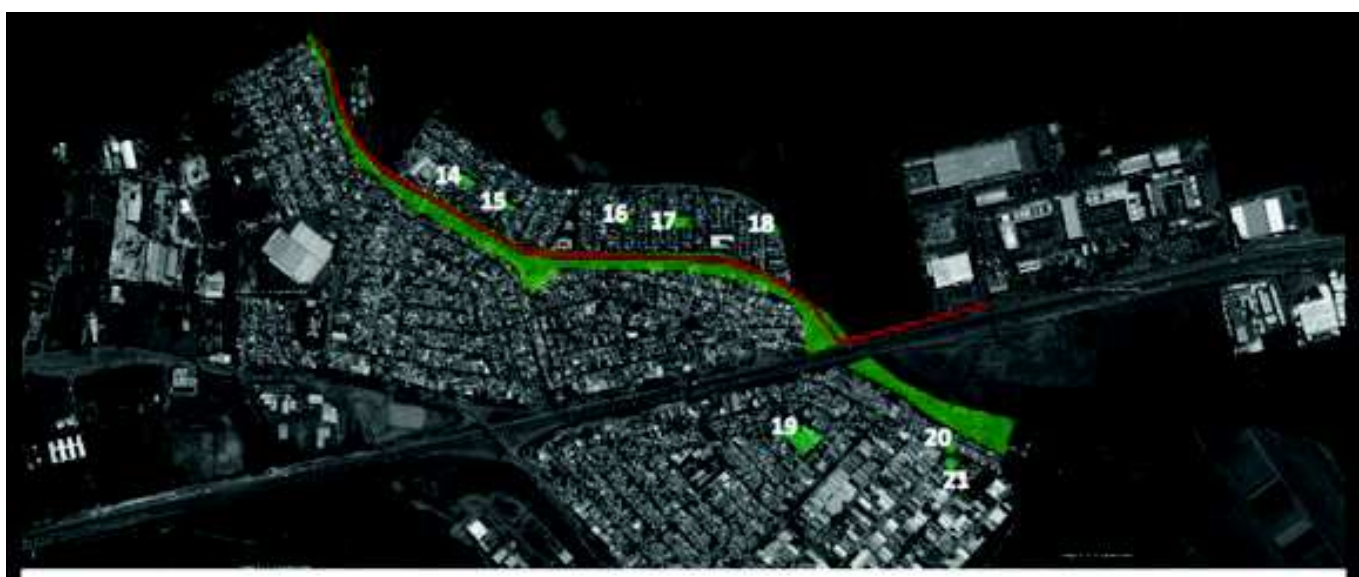

14 - Quadra esportiva e parque.

15 - Campo de futebol precario.

16 - Área verde densamente arborizada.

17 - Quadra não edificada e sem arborizaçāo.

18 - Quadra não edificada e sem arborização.

19 - Campo de futebol e quadra esportiva.

20 - Área de parque.

21 - Lote năo edificado com abertura para a entrada de carros.

Figura 13 Diretrizes de Projeto. Propostas de conexões da área do Parque Linear da Lagoa com outros espaços livres da região e de trajeto de ciclovia.

Fonte: Elaborada pela equipe do PET. 
Renata Baesso Pereira, Claudia Maria Lima Ribeiro, Adriano Bueno, Daniel Henrique Ribeiro, Danilo Pena Maia, Fernanda Martini, Maria Stella Angote, Ricardo Lazarin, Rodrigo Roda e Viviane Bestane Bartolo

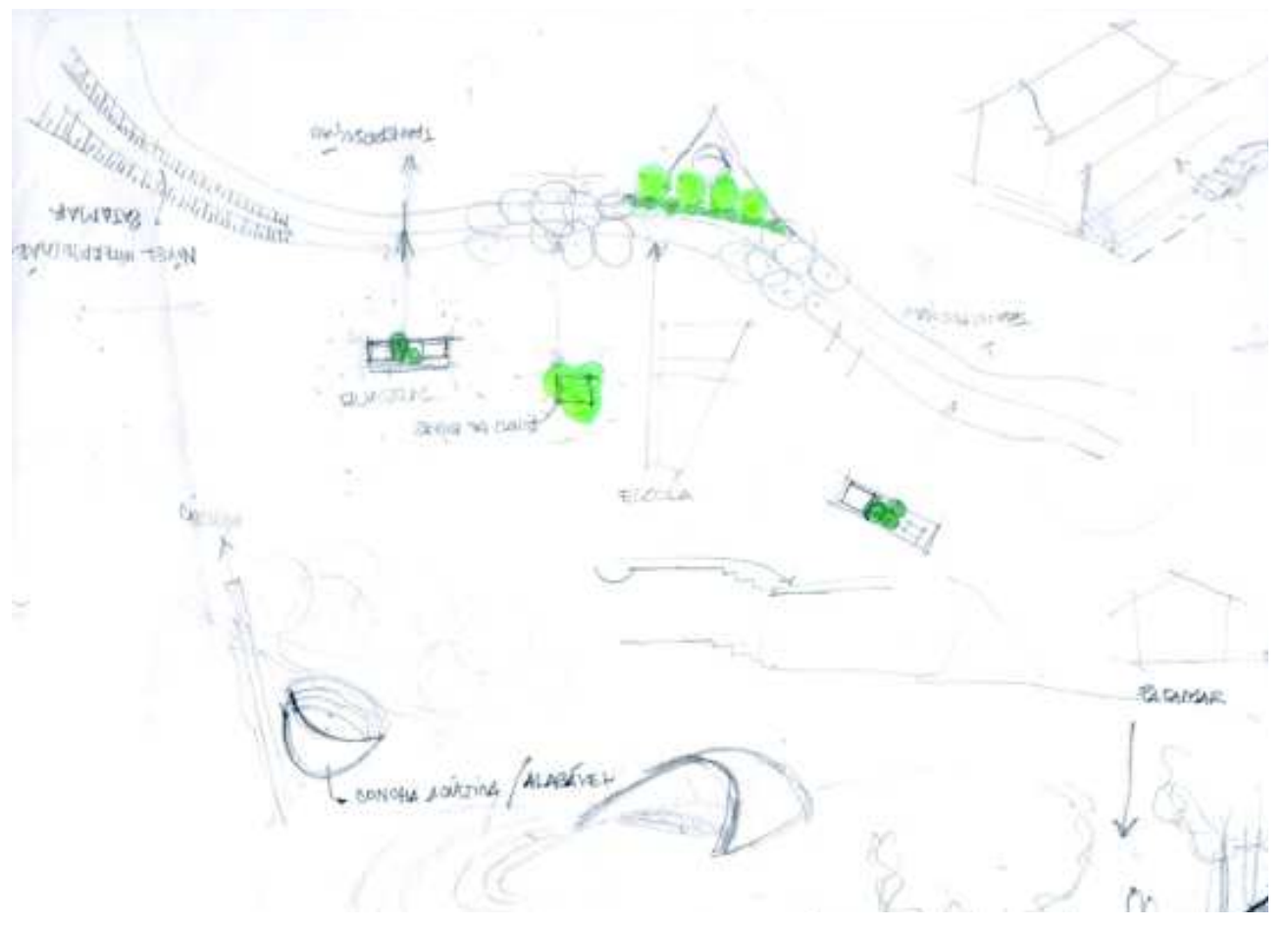

Figura 14 Croquis do Projeto.

Fonte: Elaborada pela equipe do PET.

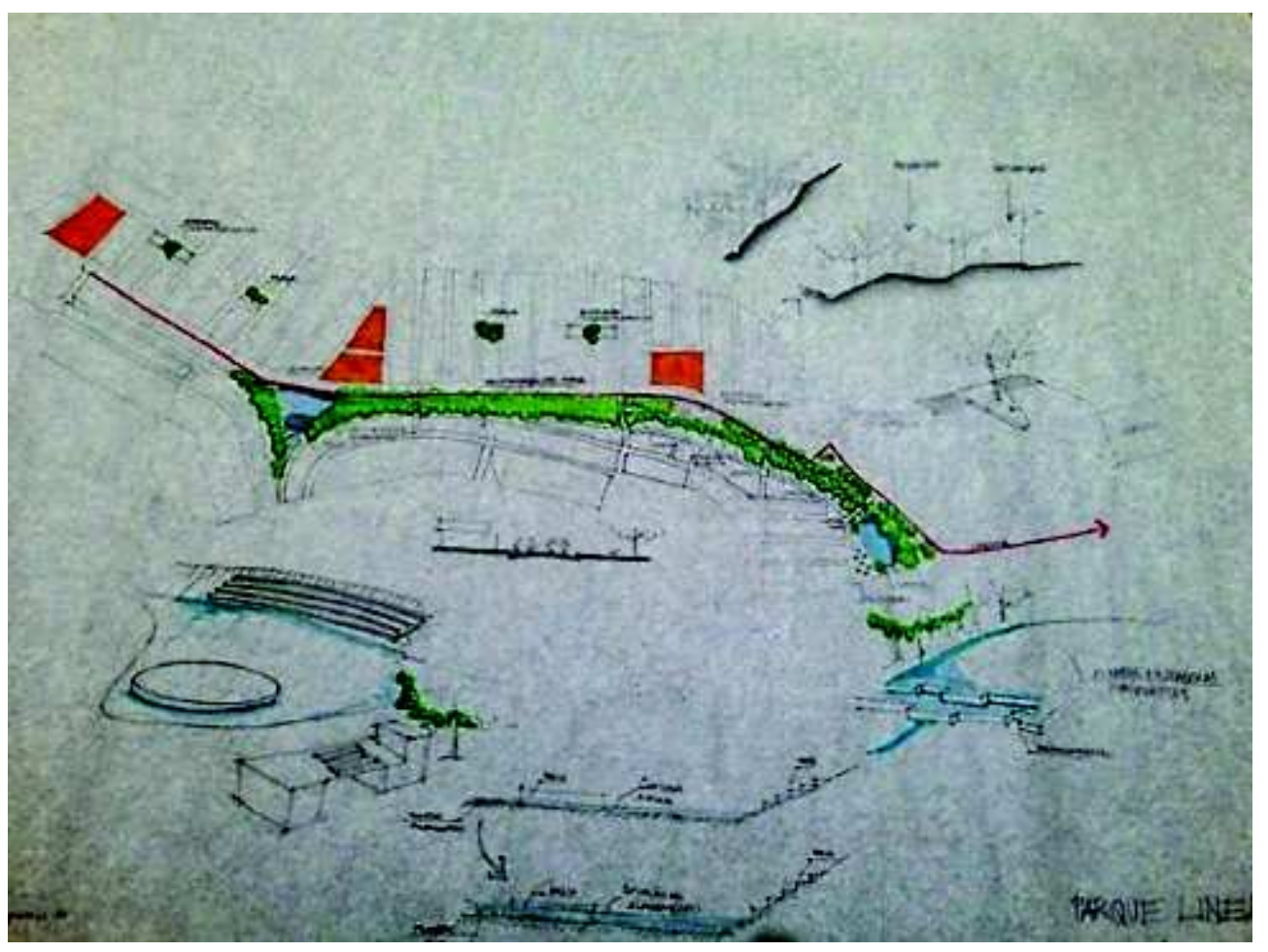

Figura 15 Estudos de conectividade do parque com equipamentos e outros espaços livres. Fonte: Elaborada pela equipe do PET. 


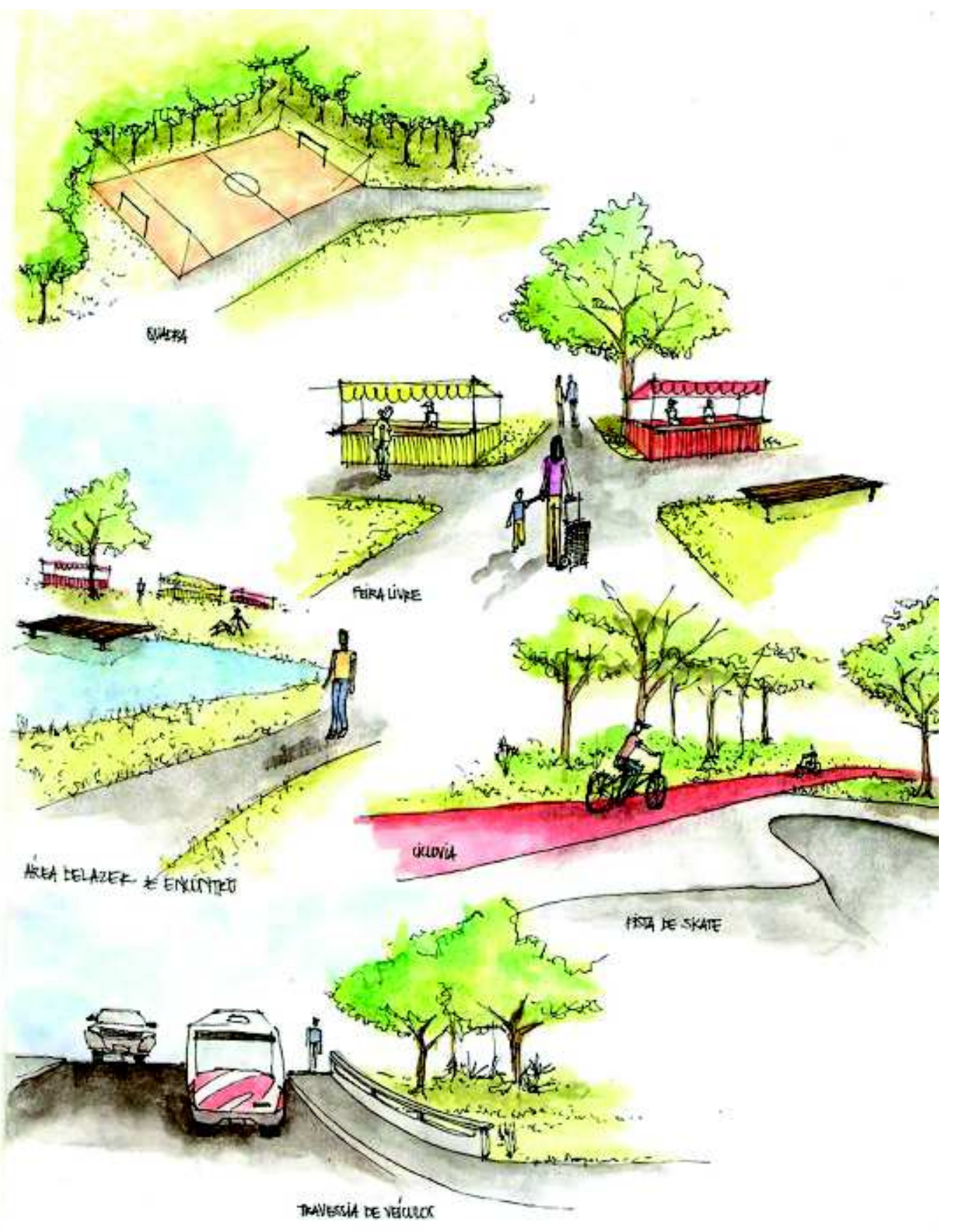

PARUE DALAGCA-CAYYFINAS-SR TET ARQUTETRA E LREANISMO

Figura 16 Estudos dos elementos propostos no projeto. Fonte: Danilo Pena Maia. 
Renata Baesso Pereira, Claudia Maria Lima Ribeiro, Adriano Bueno, Daniel Henrique Ribeiro, Danilo Pena Maia, Fernanda Martini, Maria Stella Angote, Ricardo Lazarin, Rodrigo Roda e Viviane Bestane Bartolo

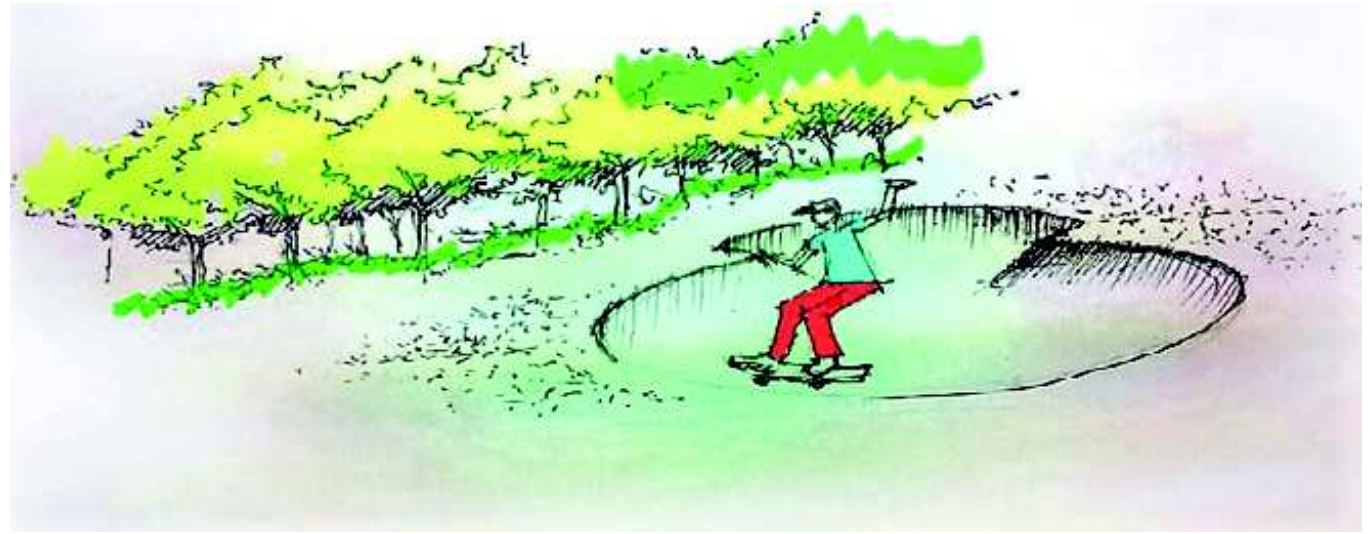

Figura 17 Estudos da pista de skate e bacia de contenção.

Fonte: Danilo Pena Maia

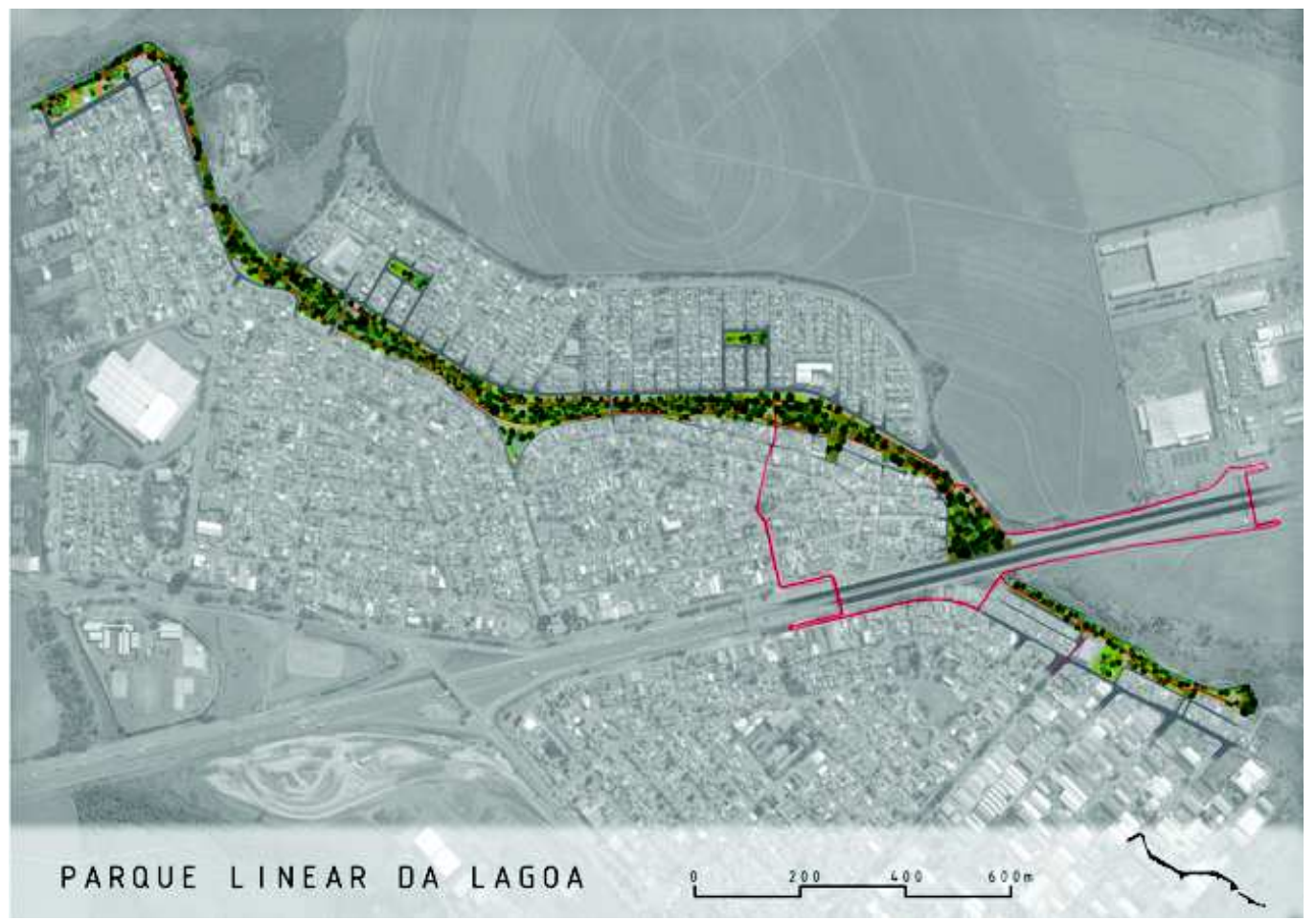

Figura 18 Projeto do parque da Lagoa - implantação geral. Fonte: Elaborada pela equipe do PET. 


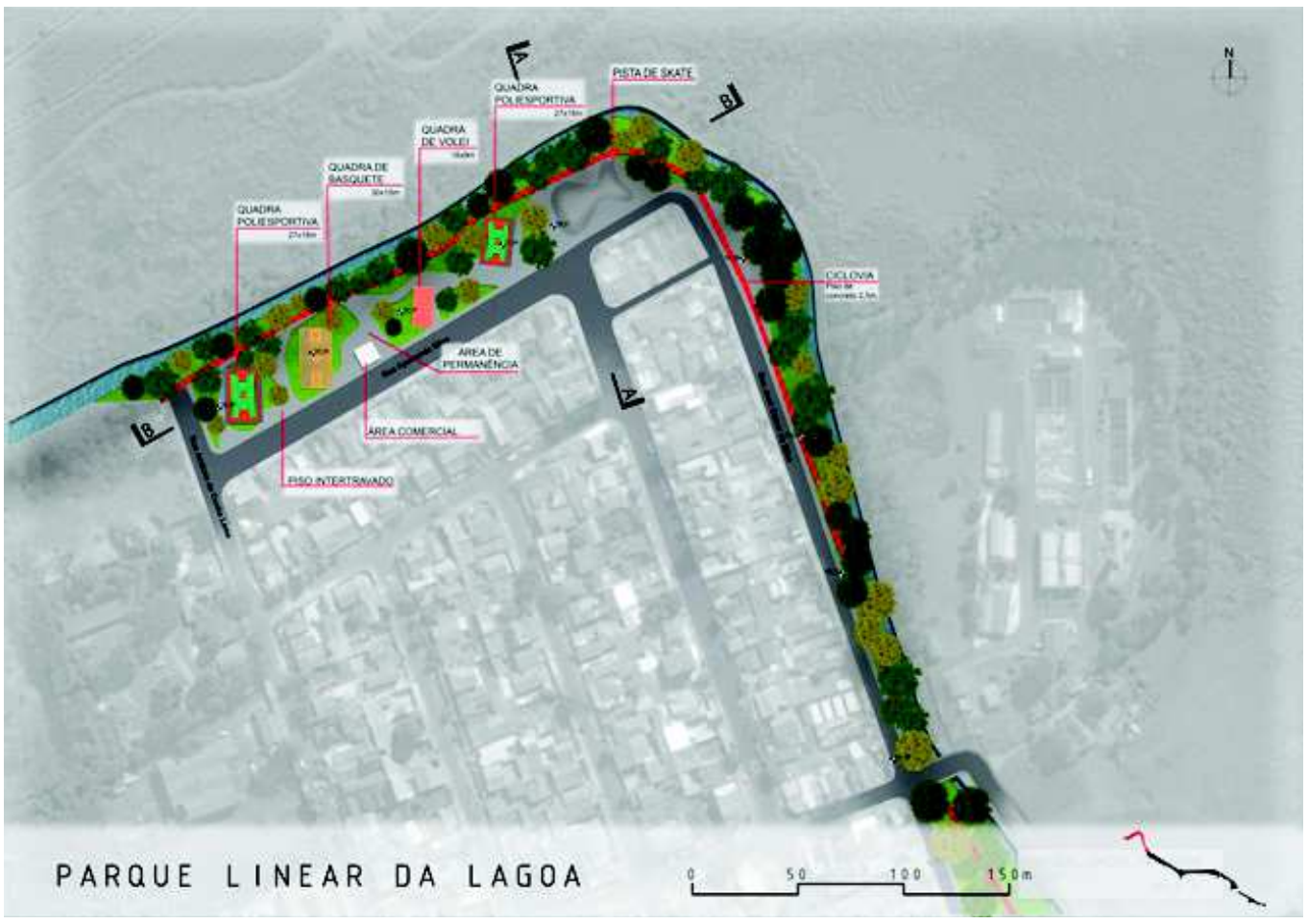

Figura 19 Projeto do parque da Lagoa - Setor 1.

Fonte: Elaborada pela equipe do PET.

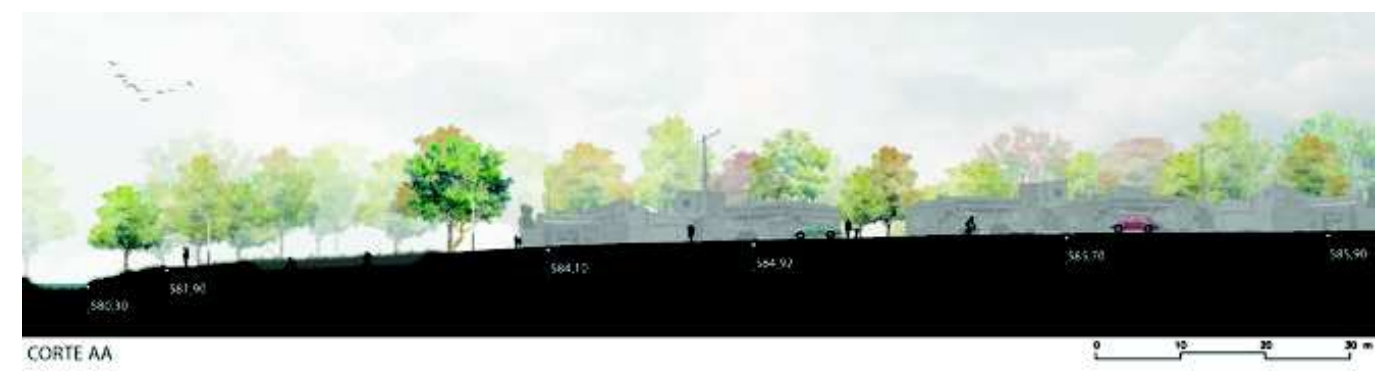

Figura 20 Projeto do parque da Lagoa - Corte AA.

Fonte: Elaborada pela equipe do PET.

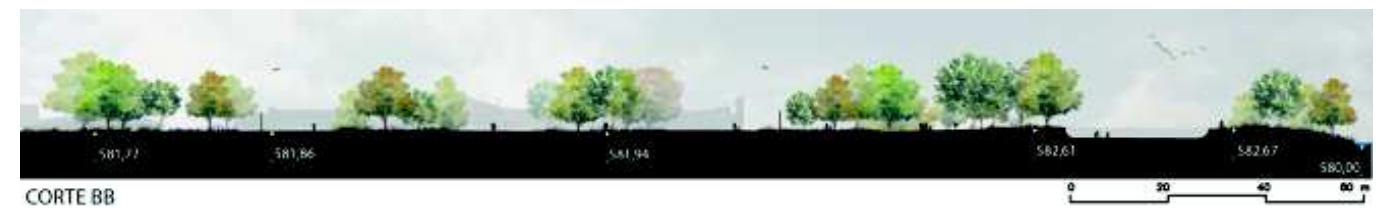

Figura 21 Projeto do Parque da Lagoa - Corte BB.

Fonte: Elaborada pela quipe do PET. 
Renata Baesso Pereira, Claudia Maria Lima Ribeiro, Adriano Bueno, Daniel Henrique Ribeiro, Danilo Pena Maia, Fernanda Martini, Maria Stella Angote, Ricardo Lazarin, Rodrigo Roda e Viviane Bestane Bartolo

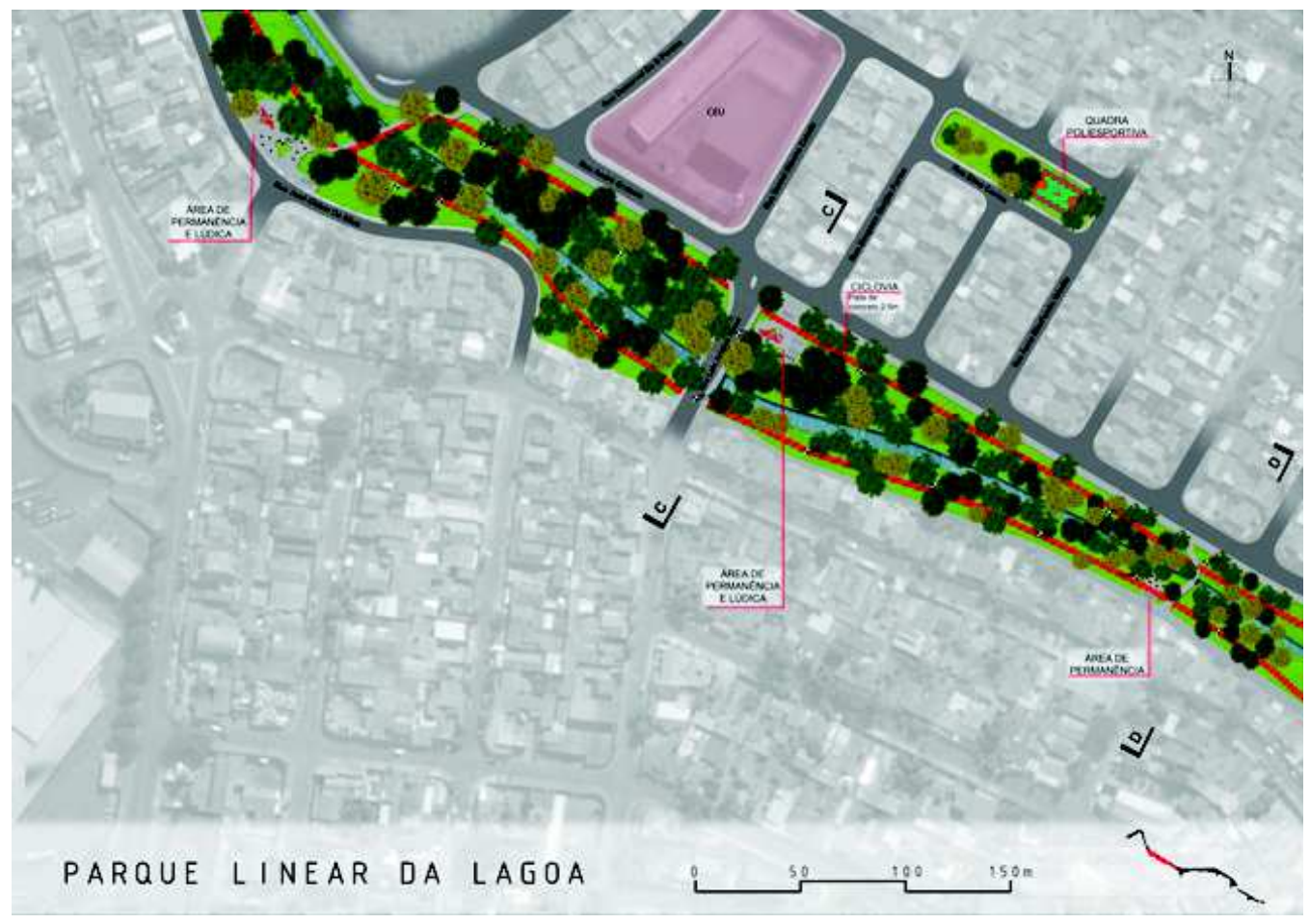

Figura 22 Projeto do parque da Lagoa - Setor 2. Fonte: Elaborada pela equipe do PET.

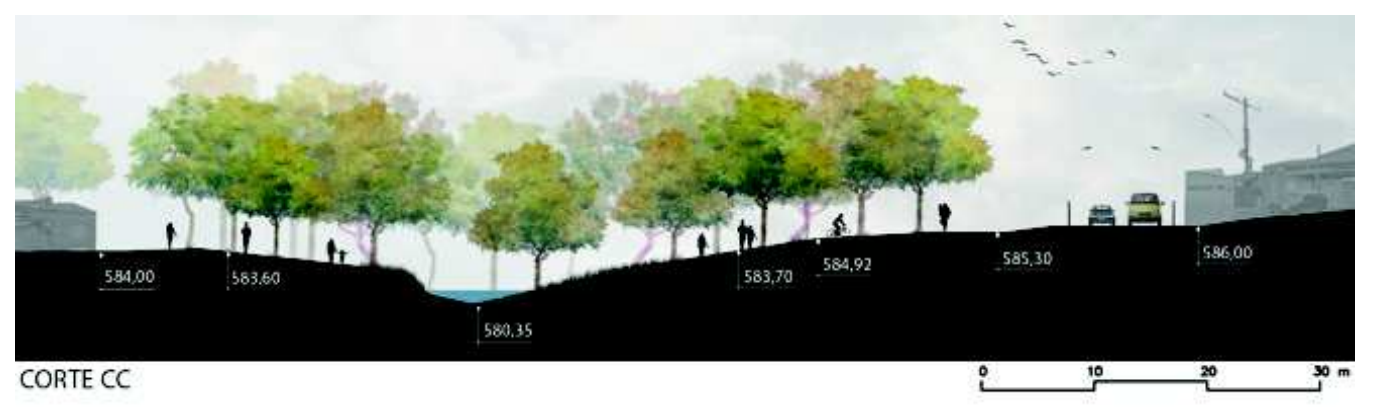

Figura 23 Projeto do parque da Lagoa - Corte CC. Fonte: Elaborada pela equipe do PET.

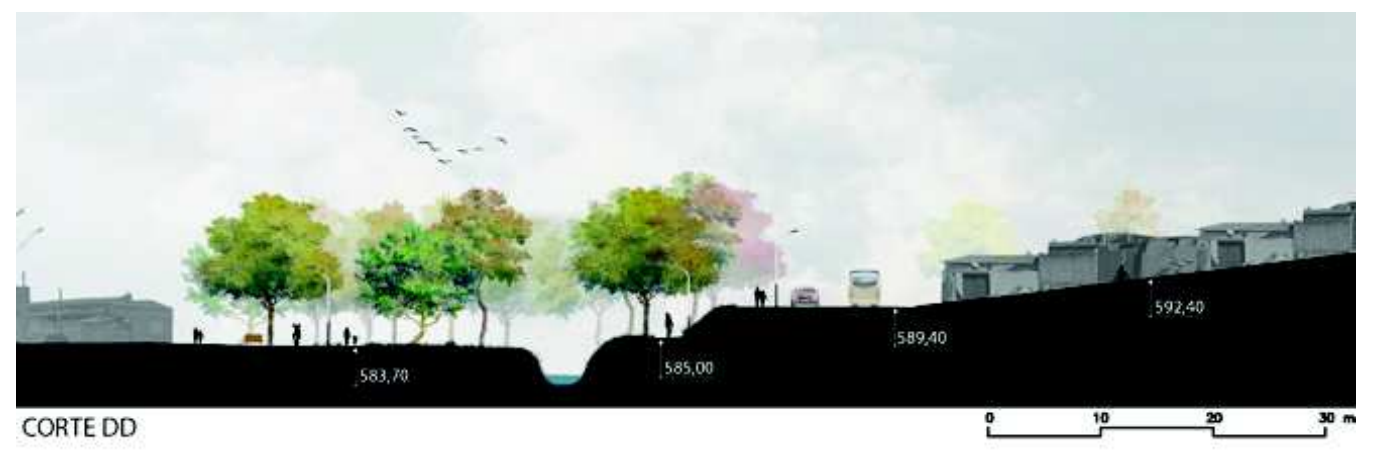

Figura 24 Projeto do parque da Lagoa - Corte DD.

Fonte: Elaborada pela equipe do PET. 


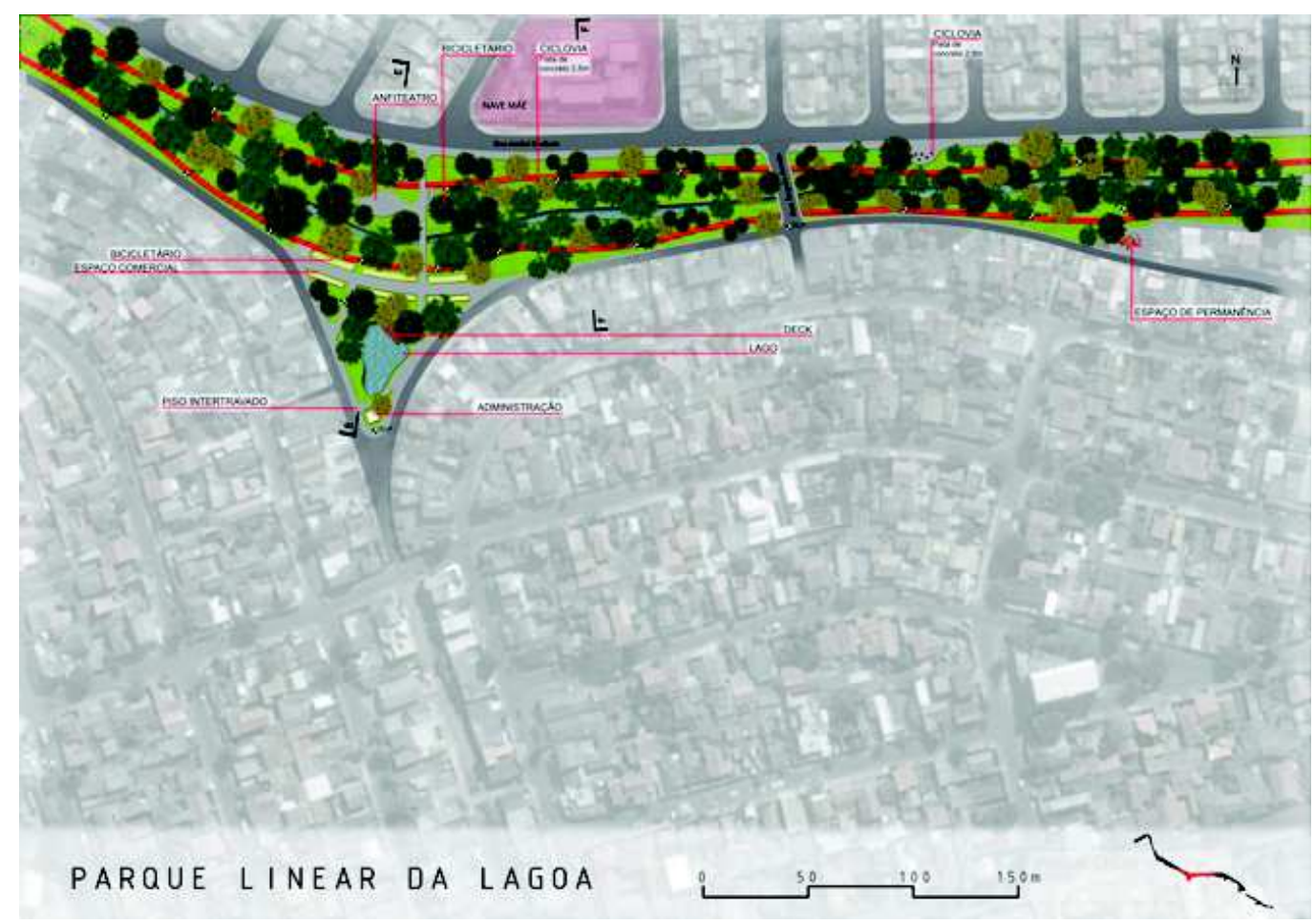

Figura 25 Projeto do parque da Lagoa - Setor 3.

Fonte: Elaborada pela equipe do PET.

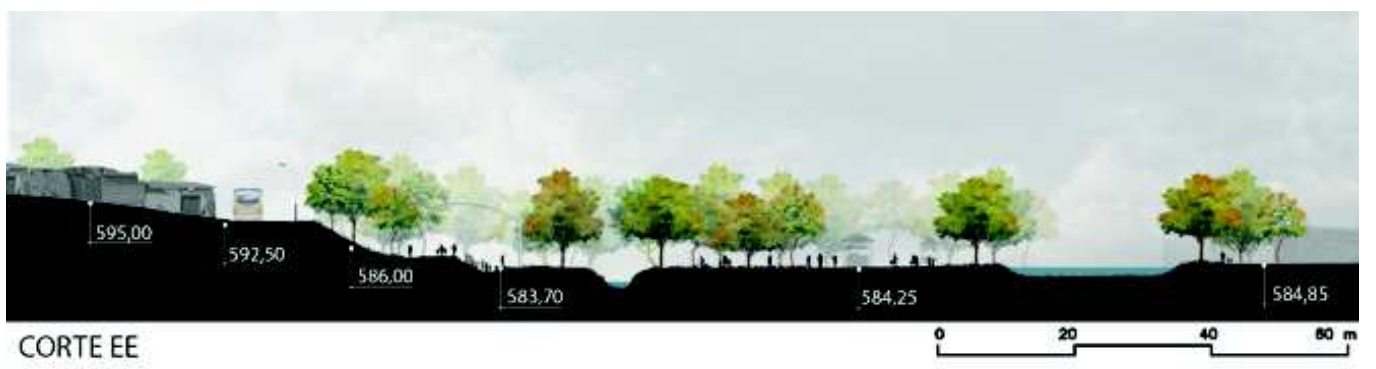

Figura 26 Projeto do parque da Lagoa - Corte EE.

Fonte: Elaborada pela quipe do PET.

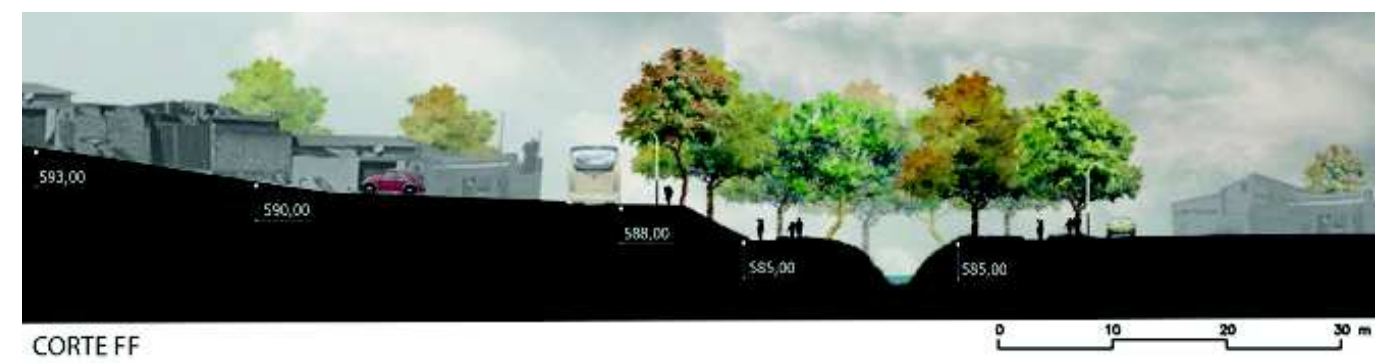

Figura 27 Projeto do parque da Lagoa - Corte FF.

Fonte: Elaborada pela equipe do PET. 
Renata Baesso Pereira, Claudia Maria Lima Ribeiro, Adriano Bueno, Daniel Henrique Ribeiro, Danilo Pena Maia, Fernanda Martini, Maria Stella Angote, Ricardo Lazarin, Rodrigo Roda e Viviane Bestane Bartolo

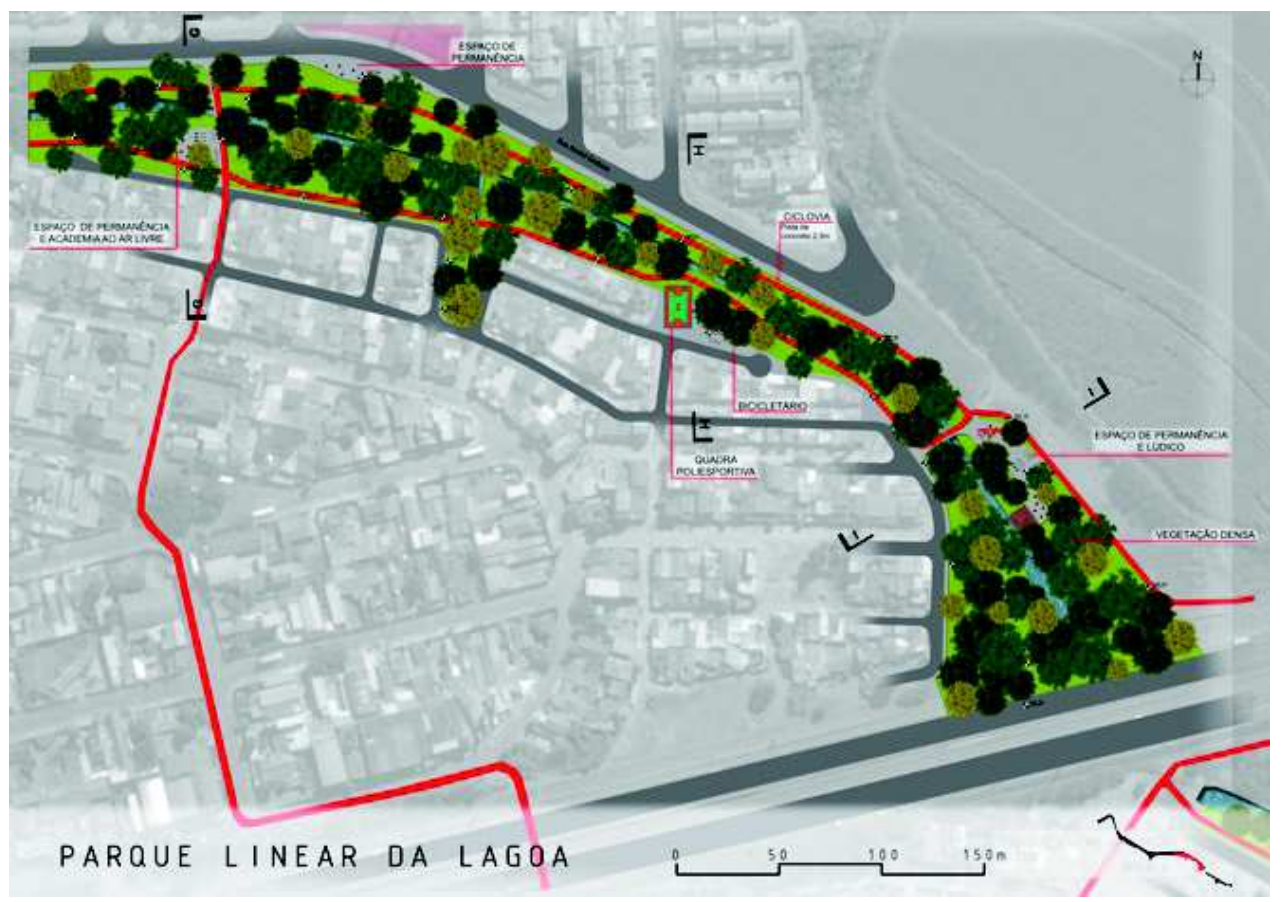

Figura 28 Projeto do parque da Lagoa - Setor 4. Fonte: Elaborada pela equipe do PET.

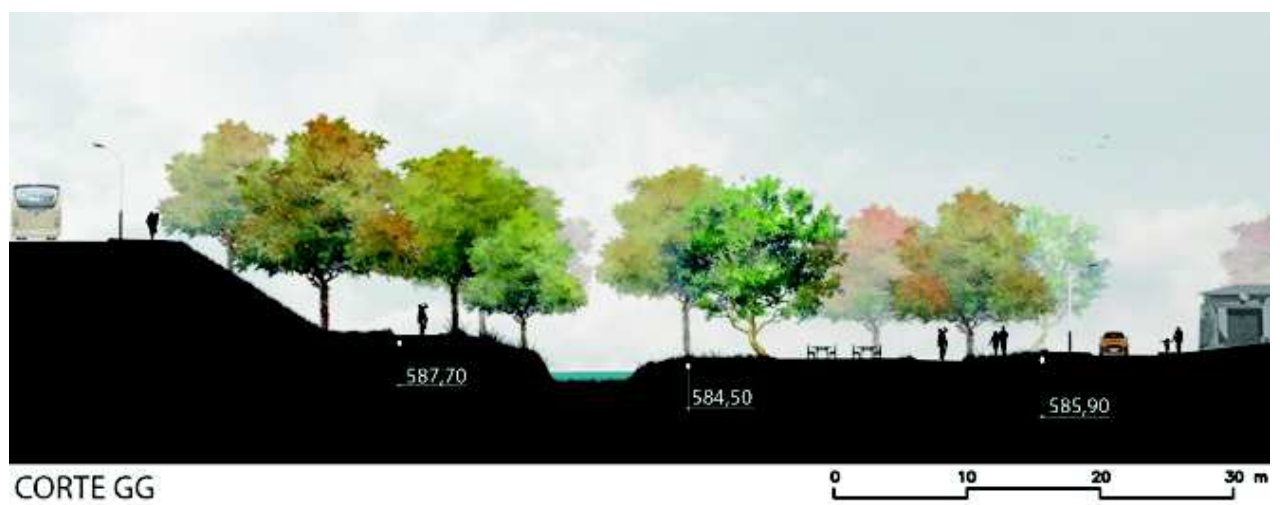

Figura 29 Projeto do parque da Lagoa - Corte GG Fonte: Elaborada pela equipe do PET.

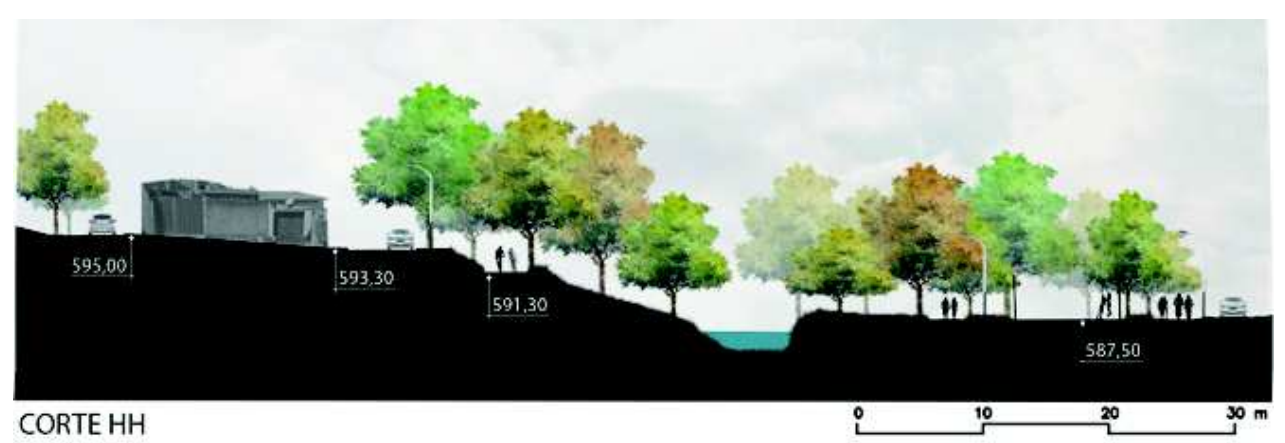

Figura 30 Projeto do parque da Lagoa - Corte HH. Fonte: Elaborada pela equipe do PET. 


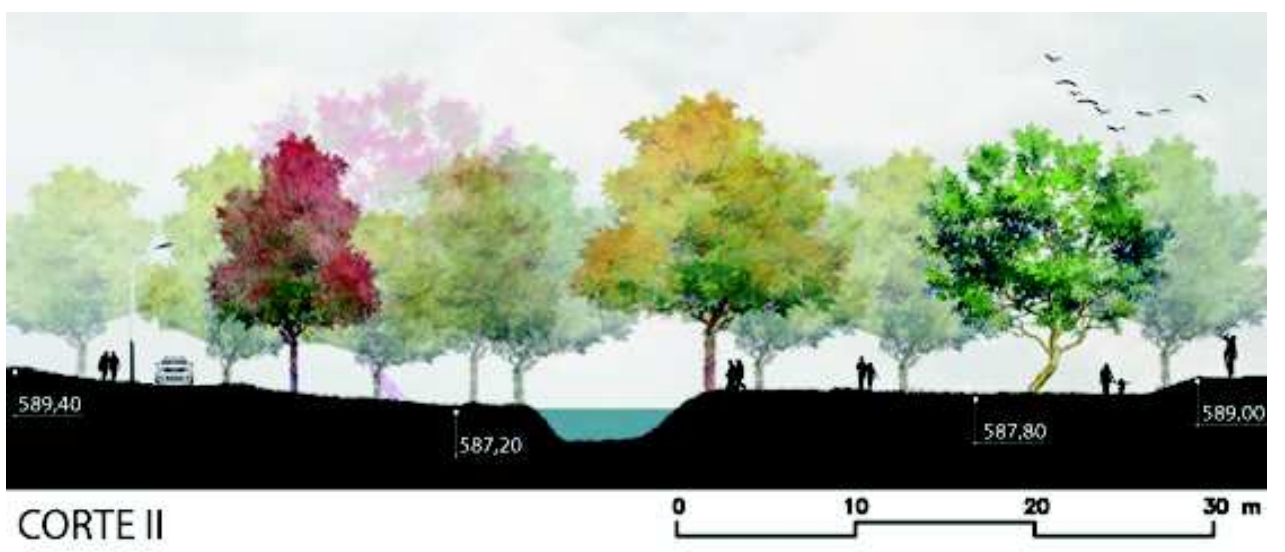

Figura 31 Projeto do parque da Lagoa - Corte II.

Fonte: Elaborada pela equipe do PET.

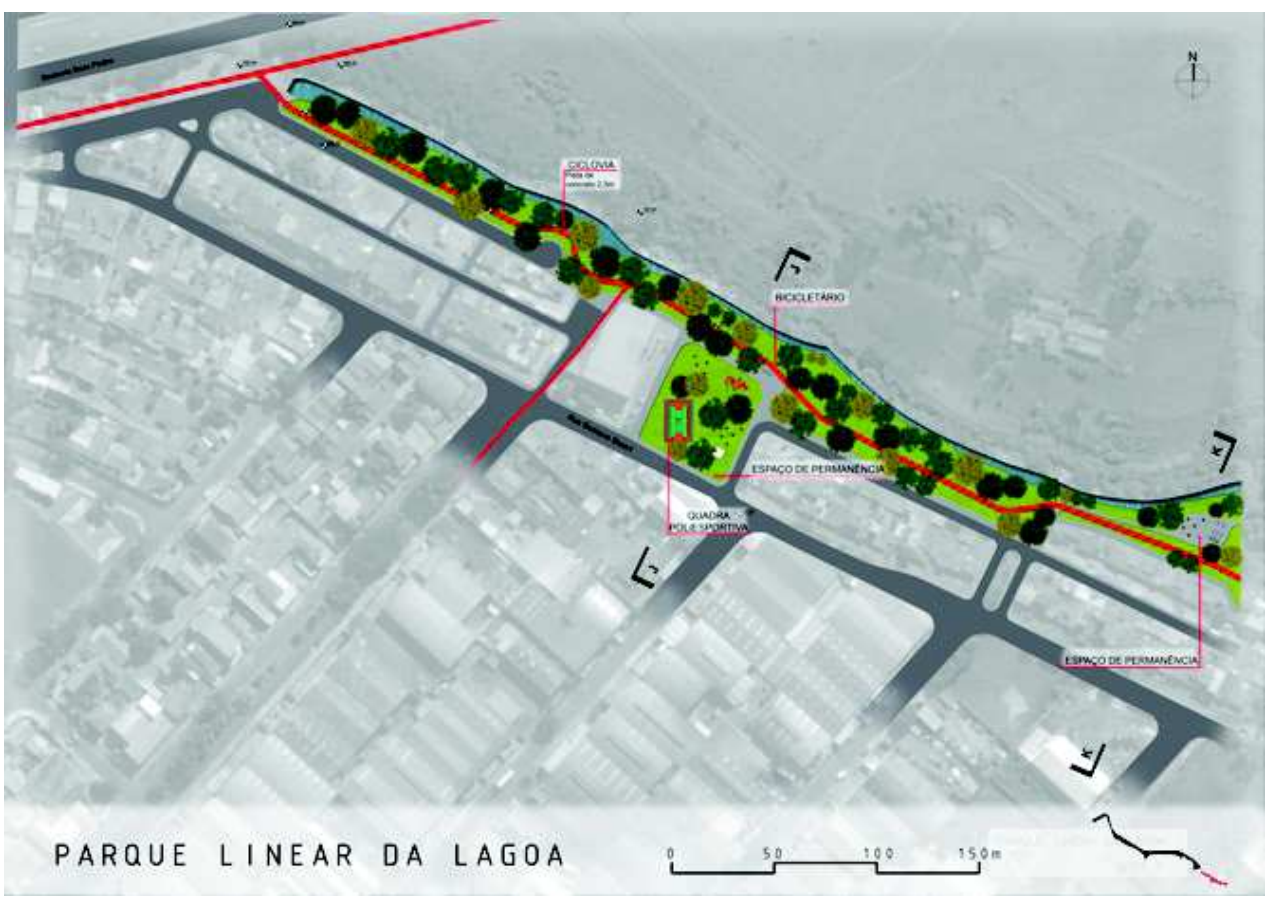

Figura 32 Projeto do parque da Lagoa - Setor 5.

Fonte: Elaborada pela equipe do PET.

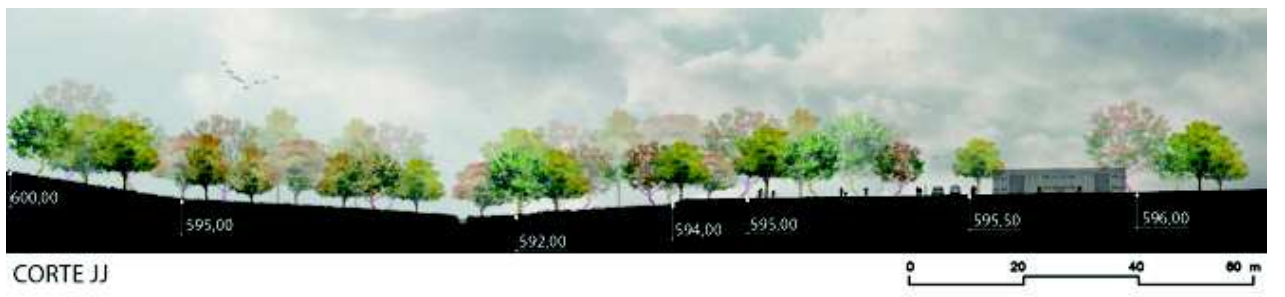

Figura 33 Projeto do parque da Lagoa - Corte JJ.

Fonte: Elaborada pela equipe do PET. 


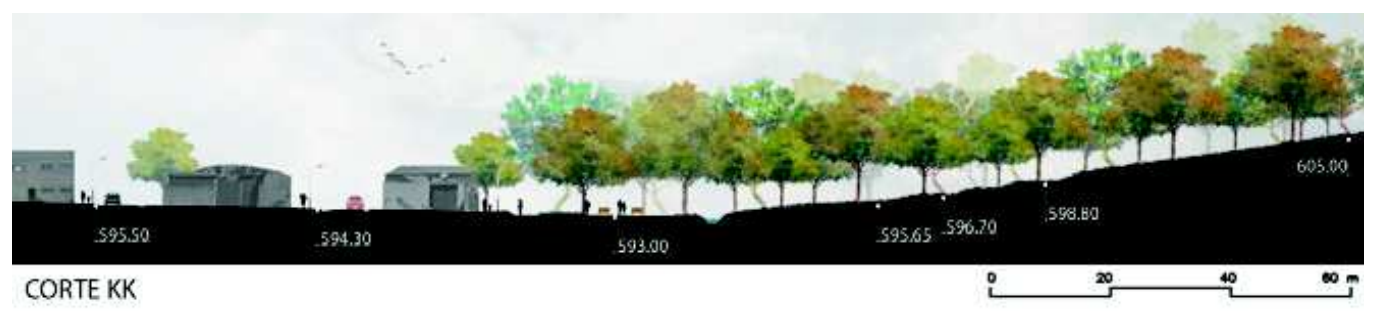

Figura 34 Projeto do parque da Lagoa - Corte KK. Fonte: Elaborada pela equipe do PET.

\section{CONSIDERAÇÕES FINAIS}

Os projetos de parques lineares mostram a importância do pensamento sistêmico na abordagem das APPs urbanas, levando em conta não apenas o sistema de drenagem, mas fatores ambientais, culturais, sociais, políticos e econômicos. Potencialmente as APPs constituem um estoque de área de ampliação do sistema de espaços livres em regiões de ocupação urbana já consolidadas.

Todo o processo que envolveu o trabalho apresentado neste artigo demonstrou o quanto a administração pública municipal de Campinas (SP) está despreparada para elaborar uma reflexão urbanística consistente, que resulte em projetos urbanos capazes de traduzir as demandas das comunidades envolvidas. Também fica evidente o quanto é superficial por parte dos agentes públicos o conhecimento dos aspectos físicos e sociais das áreas em que os parques lineares são propostos no PDM.

A equipe de projeto teve oportunidade de discutir aspectos previstos no planejamento ambiental do município em meio à realidade social do local de implantação do projeto. O confronto entre o que é bom para o nível da comunidade e o que é bom para o nível da paisagem no contexto da bacia hidrográfica suscitou reflexões importantes sobre o tratamento das APPs urbanas.

A elaboração de um projeto executivo do Parque Linear da Lagoa não foi o objetivo deste trabalho. Interessou à equipe a discussão sistêmica do tema e a investigação de sua relevância para o ensino de projeto e desenho urbano. $\bigcirc$ processo demonstrou que a formação dos alunos de arquitetura e urbanismo pode ser ampliada e aprofundada a partir do contato direto com a comunidade e os gestores públicos municipais no desenvolvimento de projetos que aliem pesquisa e extensão. 


\section{REFERÊNCIAS BIBLIOGRÁFICAS}

ANDRADE, Liza Maria S. de. Conexões dos padrões espaciais dos ecossistemas urbanos: a construção de um método com enfoque transdisciplinar para o processo de desenho urbano sensível à água no nível da comunidade e da paisagem. 2014. 544 f. Tese (Doutorado em Arquitetura e Urbanismo) - Faculdade de Arquitetura e Urbanismo da Universidade de Brasília, Brasília, 2014.

BENFATTI, Denio; SILVA, Jonathas Magalhães Pereira da. Legislação ambiental e urbanística: contradições e possibilidades de diálogo na qualificação do sistema de espaços livres urbanos do município de Campinas. In: Encontros Nacionais da ANPUR, Anais... v. 15, 2013, p. 1-21

BRASIL. Estatuto da Cidade: Lei $n^{\circ}$ 10.257, de 10 de julho de 2001, que estabelece diretrizes gerais da política urbana. Brasília, Câmara dos Deputados, Coordenação de Publicações, 2001. Disponível em: <http://www2. camara.leg.br/atividade-legislativa/comissoes/comissoes-permanentes/cdu/part.html/estatutodacidade.pdf $>$. Acesso em: 21 out. 2016.

Medida Provisória No 2166-67, de 2001. Altera os artigos $1^{\circ}, 4^{\circ}, 14,16$ e 44, e acresce dispositivos à Lei $\overline{n^{\circ} 4.771}$, de 15 de setembro de 1965, que institui o Código Florestal, bem como altera o art. 10 da Lei $n^{\circ} 9.393$, de 19 de dezembro de 1996, que dispõe sobre o Imposto sobre a Propriedade Territorial Rural - ITR. Brasília, DF, 2001. Disponível em: <http://www2.camara.leg.br/legin/fed/medpro/2001/medidaprovisoria-2166-67-24agosto-2001-393708-publicacaooriginal-1-pe.html>. Acesso em: 21 out. 2016.

(2006). RESOLUÇÃO CONAMA n 369 de 28 de março de 2006. Dispõe sobre os casos excepcionais, de utilidade pública, interesse social ou baixo impacto ambiental, que possibilitam a intervenção ou supressão de vegetação em Área de Preservação Permanente-APP. Diário Oficial da União, 29 de mar, 2006, Seção 1, páginas 150-151.

CAMPINAS (2006). Lei Complementar n 15 de 27 de dezembro de 2006. Dispõe sobre o Plano Diretor. Campinas (SP), 2006. Diário Oficial do Município, n 9.074, 29 dez. 2006, p. 3-12.

. (2010). Projeto de Lei Complementar n 17/2010. Dispõe sobre o Plano Local de Gestão da Macrozona 9 - MZ9 - Área de Integração Noroeste - AIN do Município de Campinas. Campinas, 2010. Disponível em: <http:// www.campinas.sp.gov.br/governo/seplama/planos-locais-de-: gestao/doc/projeto_lei_complementar_MZ9.pdf>. Acesso em: 4 out. 2016.

COSTA, Heloisa Soares de Moura; CAMPANATE, Ana Lúcia Goyatá; ARAÚJO, Rogério Palhares Zschaber. A dimensão ambiental nos Planos Diretores de Municípios brasileiros. In: SANTOS JUNIOR, Orlando Alves dos; MONTANDON, Daniel Todtmann (Orgs). Os Planos Diretores Municipais Pós-Estatuto da Cidade: balanço crítico e perspectivas. Rio de Janeiro: Rede de Avaliação e Capacitação para Implementação dos Planos Diretores Participativos. Ministério das Cidades/SNPU, 2011.

FAU PUC-CAMPINAS. Projeto Pedagógico - 2008. Aprovado na $79^{a}$ reunião da Câmara de Graduação, em 21/06/2007, e na $418^{a}$ reunião do CONSUN, em 26/06/2007, com adequações no $9^{\circ}$ e $10^{\circ}$ períodos - 2012 (aprovada pelo Conselho da Faculdade, 05/09/ 201 1, pelo Conselho de Centro, na 124a reunião, realizada em 08/09/2011 e pelo CONSUN, em sua 472a reunião, realizada em 24 nov. 2011.

FERREIRA, Ana Cristina; MARTINS, Jaime Florêncio; FREITAS, Renata Nascimento. A experiência do Programa de Educação Tutorial. In: MARTINS, Iguatemy L.; KETZER, Solange M (Org.). PET - Programa de Educação Tutorial: estratégia para o desenvolvimento da graduação. Brasília: Ministério da Educação, 2007.

MACEDO, Silvio Soares; QUEIROGA, Eugenio Fernandes; DEGREAS, Helena Napoleon. APPs urbanas uma oportunidade de incremento da qualidade ambiental e do sistema de espaços livres na cidade brasileira: conflitos e sucessos. In: SEMINÁRIO NACIONAL SOBRE ÁREAS DE PRESERVAÇÃO PERMANENTE EM MEIO URBANO: ABORDAGENS, CONFLITOS E PERSPECTIVAS NAS CIDADES BRASILEIRAS, 2, 2012, Natal, Anais... Rio

Grande do Norte, 2012. Disponível em: <http://unuhospedagem.com.br/revista/rbeur/index.php/APP/article/ view/4033>. Acesso em: 5 mar. 2016.

MAGNOLI, Miranda Martinelli. Espaço livre - objeto de trabalho. Paisagem Ambiente: ensaios. São Paulo: FAUUSP, n. 21, 2006, p. 175-198.

MARTINS, Iguatemy L. Educação Tutorial no ensino presencial: uma análise sobre o PET. In: MARTINS, Iguatemy L.; KETZER, Solange M (Org.). PET - Programa de Educação Tutorial: estratégia para o desenvolvimento da graduação. Brasília: Ministério da Educação, 2007.

\section{Nota do editor}

Submissão: 15 jul. 2015

Aprovação: 16 mar. 2016 